\title{
Halides of Titanium in Lower Oxidation States
}

\begin{tabular}{|r|l|}
\hline Journal: & Zeitschrift für Anorganische und Allgemeine Chemie \\
\hline Manuscript ID: & zaac. 200900086 \\
\hline Wiley - Manuscript type: & Research Report \\
\hline Author: & 03-Feb-2009 \\
\hline Komplete List of Authors: & $\begin{array}{l}\text { Meyer, Gerd; Universitaet zu Koeln, Institut fuer Anorganische } \\
\text { Chemie } \\
\text { Gloger, Thomas; Universitaet zu Koeln, Institut fuer Anorganische } \\
\text { Chemie } \\
\text { Beekhuizen, Jan; Universitaet zu Koeln, Institut fuer Anorganische } \\
\text { Chemie }\end{array}$ \\
\hline Keywords: & $\begin{array}{l}\text { Titanium, Dihalides, Trihalides, Complex halides, Cluster } \\
\text { compounds }\end{array}$ \\
\hline
\end{tabular}

\section{$\checkmark$ ScholaroNE \\ Manuscript Central}




\title{
Research Report
}

\section{Halides of Titanium in Lower Oxidation States}

\author{
Gerd Meyer,*;a] Thomas Gloger and Jan Beekhuizen
}

Keywords: Titanium; Dihalides; Trihalides; Complex halides; Clusters

\begin{abstract}
New investigations on the di- and trihalides of titanium, $\mathrm{TiX}_{2}$ and $\mathrm{TiX}_{3}(\mathrm{X}=\mathrm{Cl}, \mathrm{Br}$, I), with their $3 \mathrm{~d}^{2}$ and $3 \mathrm{~d}^{1}$ electronic configurations, confirm the early observations and conclusions of Klemm. At sufficiently low temperatures, Ti-Ti single bonds are formed in the one-dimensional trihalides, i.e., Ti-Ti dimers are observed. Equally, in the two-dimensional dihalides, $\left\{\mathrm{Ti}_{3}\right\}$ triangles occur with three single bonds. Phase transitions were detected from single-crystal or powder X-ray diffraction data, from magnetic measurements and thermal analysis. Except for the binary halides a number of ternary halides $\mathrm{ATiX}_{3}$ (extended chains of face-sharing octahedra), $\mathrm{K}_{4} \mathrm{Ti}_{3} \mathrm{Br}_{12}$ (triples of face-sharing octahedra), $\mathrm{Na}_{2} \mathrm{Ti}_{3} \mathrm{Cl}_{8}$ (triangular trimers), $\mathrm{A}_{3} \mathrm{Ti}_{2} \mathrm{X}_{9}$ (dimers of face-sharing octahedra), and $\mathrm{A}_{3} \mathrm{TiX}_{6}$ (isolated octahedra) as well as the mixed-valent halides $\mathrm{CsTi}_{2} \mathrm{I}_{7}$ (tetrahedra and octahedra) and $\mathrm{Na}_{5} \mathrm{Ti}_{3} \mathrm{Cl}_{12}$ (chains of octahedra) have been observed. Except for the triangles in titanium(II) halides, cluster compounds are rare but include $\left.\mathrm{K}_{4}\left[\left\{\mathrm{OTi}_{4}\right\} \mathrm{I}_{12}\right\}\right]$ and $\left\{\mathrm{CTi}_{6}\right\} \mathrm{Cl}_{14}$.
\end{abstract}

* Prof. Dr. Gerd Meyer

E-mail: gerd.meyer@uni-koeln.de

[a] Universität zu Köln, Department für Chemie Institut für Anorganische Chemie Greinstraße 6, D-50939 Köln, Germany Fax: (49) 2214705083 www.gerdmeyer.de 


\section{Introduction}

In accord with its position in the periodic table as a group 4 element and, therefore, its electronic configuration [Ar] $4 \mathrm{~s}^{2} 3 \mathrm{~d}^{2}$, titanium appears in simple halides in the oxidation states $+4,+3$, and +2 . Of these, the oxidation states +3 and +2 are the most interesting because there titanium has one $\left(3 \mathrm{~d}^{1}\right)$ and two $\left(3 \mathrm{~d}^{2}\right)$ unpaired electrons, respectively. This gives, at sufficiently high temperatures, rise to paramagnetism. At low temperatures, collective magnetic effects may appear, or, as in the case of the titanium(II) and titanium(III) halides, chemical bonding may emerge.

First work on lower-valent titanium halides dates back to the early years of the twentieth century [1]. But only in the forties, thorough preparative work combined with magnetic measurements shed considerable light on the nature of these halides. It was Wilhelm Klemm who found that the magnetic moments dropped to low values at low temperatures, depending upon the anion $\mathrm{X}^{-}=\mathrm{Cl}^{-}, \mathrm{Br}^{-}, \mathrm{I}^{-}$, in both dihalides and trihalides, $\mathrm{TiX}_{2}$ [2] and $\mathrm{TiX}_{3}$ [3]. The drop of the magnetic moments is accompanied by a reduction of the molar volumes. Klemm has interpreted this observation as the formation of covalent bonds (or, alternatively, as antiferromagnetic behaviour).

\section{Binary halides, $\mathrm{TiX}_{3}$ and $\mathrm{TiX}_{2}$}

\subsection{Titanium(III) halides: $d^{1}$ systems}

The structural topology of the trihalides of titanium, $\mathrm{TiX}_{3}$ with $\mathrm{X}=\mathrm{Cl}, \mathrm{Br}$, I, can be deduced from a hexagonal closest packing of spheres, i.e., of halide ions. One third of the octahedral voids are filled with $\mathrm{Ti}^{3+}$ cations, in a way that the filled [TiX 6 ] octahedra share common faces, in accord with the Niggli formula $\mathrm{TiX}_{6 / 2}$. The chains thus formed run parallel to the hexagonal $c$ axis in the high-temperature modification named, in the following, $\mathrm{TiX}_{3}$-II (hexagonal, $\mathrm{P} 6_{3} / \mathrm{mcm}$ ), see Fig. 1.

For $\mathrm{TiI}_{3}$, structural investigations were carried out by Holze [4] and v. Schnering [5]. This latter investigation, carried out by single-crystal X-ray crystallography, exhibited for $\mathrm{TiI}_{3}$ the hexagonal space group $\mathrm{P} 6_{3} / \mathrm{mcm}$. Thus, Ti-Ti bonds cannot be present as these would lead to a symmetry reduction to Pmmn (orthorhombic), see for example [6]. This low-temperature modification, $\mathrm{MX}_{3}$-I, was observed so far for $\mathrm{ZrI}_{3}$ [7], $\mathrm{MoX}_{3}\left(\mathrm{X}=\mathrm{Br}\right.$, I) [8], $\mathrm{RuCl}_{3}$ [6], $\mathrm{RuBr}_{3}$ [9], and $\mathrm{OsI}_{3}$ [10]. Chains of $\left[\mathrm{MX}_{6}\right]$ octahedra run along the orthorhombic $b$ axis and the $\mathrm{M}-\mathrm{M}$ distances are not equidistant anymore as in $\mathrm{MX}_{3}-\mathrm{II}$.

The crystal structures of $\mathrm{TiBr}_{3}-\mathrm{I}$ and $\mathrm{TiI}_{3}-\mathrm{I}$ were determined from single-crystal data at ambient temperature [11]. Ti-Ti distances are 292.3(7) and 315.7(7) pm for $\mathrm{TiBr}_{3}-\mathrm{I}$ and 309.6(2) and 339.6(2) pm for $\mathrm{TiI}_{3}-\mathrm{I}$, respectively. The respective distances for the higher homologue $\mathrm{ZrI}_{3}$ are 317.2(2) and 350.7(2) pm, subject to the larger zirconium atom. Luckily, it was also possible to collect data sets for $\mathrm{TiI}_{3}$ in the temperature range of 183 to $448 \mathrm{~K}$ [11]. Fig. 2 shows the Ti-Ti distances derived therefrom versus temperature. An analysis of these data deduces a second-order phase transition at $317 \mathrm{~K}$ with an (equidistant) $\mathrm{Ti}-\mathrm{Ti}$ distance of $326 \mathrm{pm}$ at that temperature. These results are confirmed by a recent study of the structures and phase transition of $\mathrm{TiI}_{3}[12]$.

Figure 1. Crystal structure of the high-temperature modification of the titanium trihalides, $\mathrm{TiX}_{3}-\mathrm{II}(\mathrm{X}=\mathrm{Cl}, \mathrm{Br}, \mathrm{I})$; right: part of one chain of $\left[\mathrm{TiX}_{6}\right]$ octahedra sharing common faces.

Figure 2. Ti-Ti distances versus temperature for $\mathrm{TiI}_{3}$ from single-crystal X-ray data. 
This phase transition (II $\rightarrow$ I) can be interpreted as a Peierls distortion arising from degenerate partially filled $d$ bands at sufficiently high temperatures. At lower temperatures, the band structure of $\mathrm{TiI}_{3}$-I shows a strong splitting of these $\mathrm{d}$ bands (see, e.g., at the $\Gamma(\mathrm{G})$ point, Fig. 3) which is due to attractive interactions (covalent bonds; antiferromagnetic coupling) between the titanium atoms right below the Fermi level. From a molecular orbital point of view, $\sigma$ bonds are present between every second pair of titanium atoms (Fig. 3 ).

Figure 3. Band structure of $\mathrm{TiI}_{3}$-I from a DFT-LMTO ASA calculation (left); molecular orbitals from Extended Hückel MO calculations (right).

\subsection{Titanium(II) halides: $d^{2}$ systems}

The titanium dihalides $\mathrm{TiX}_{2}$ with $\mathrm{X}=\mathrm{Cl}, \mathrm{Br}$, I crystallize at sufficiently high temperatures with the $\mathrm{CdI}_{2}$ type of structure. Thus the crystal structures of $\mathrm{TiX}_{3}$ and $\mathrm{TiX}_{2}$ are closely related to each other. They both exhibit a hexagonal closest packing of halide ions with one third of the octahedral interstices occupied between every adjacent layer as in $\mathrm{TiX}_{3}$ and all octahedral interstices occupied between every second layer as in $\mathrm{TiX}_{2}$. Thereby all [ $\left.\mathrm{TiX}_{6}\right]$ octahedra share common edges to form a two-dimensional layer according to the Niggli formula $\mathrm{TiX}_{6 / 3}$. A $3^{6}$ net of titanium atoms is thus formed with all titanium atoms equidistant at sufficiently high temperatures, modification $\mathrm{TiX}_{2}$-II (Fig. 4, left).

Figure 4. Crystal structure of the high-temperature modification of titanium dibromide, $\mathrm{TiBr}_{2}-\mathrm{II}$, and one $\left[\mathrm{Ti}_{3} \mathrm{Br}_{13}\right]$ unit formed within the $\mathrm{Br}-\mathrm{Ti}-\mathrm{Br}$ slabs (right) of $\mathrm{TiBr}_{2}-\mathrm{I}$ upon cooling.

Upon cooling the $3^{6}$ net of $\mathrm{Ti}^{2+}$ distorts such that titanium triangles occur. These triangles are surrounded by thirteen halide ions and are further connected to the two-dimensional X-Ti$\mathrm{X}$ slab as is typical for the $\mathrm{CdI}_{2}$ type of structure. These $\left[\mathrm{Ti}_{3} \mathrm{X}_{13}\right]$ units (Fig. 4) are topologically also seen in $\mathrm{Nb}_{3} \mathrm{X}_{8}$ [13] and in $\mathrm{Na}_{2} \mathrm{Ti}_{3} \mathrm{Cl}_{8}$ [14], see below.

The phase transition $\mathrm{TiX}_{2}$-II $\rightarrow \mathrm{TiX}_{2}$-I can thus be understood as a two-dimensional Peierls distortion where a symmetry reduction from $\mathrm{P}-3 \mathrm{~m} 1$ ( $\mathrm{TiX}_{2}-\mathrm{II}, \mathrm{CdI}_{2}$ type) to $\mathrm{P} 3$ ( $\left.\mathrm{TiX}_{2}-\mathrm{I}\right)$ takes place with the hexagonal $a$ axis enlarged by $\sqrt{3}$. While the crystal structure of $\mathrm{TiI}_{2}-\mathrm{II}_{\mathrm{I}}$ could be determined by powder neutron diffraction $[a=412.72(2), c=684.74(2) \mathrm{pm}, \mathrm{P}-3 \mathrm{~m} 1$, $\left.Z=1, \mathrm{~T}=127 \mathrm{~K}, \mathrm{z}(\mathrm{I})=0.2409(1), \mathrm{R}_{\mathrm{p}}=0.045, \mathrm{R}_{\mathrm{wp}}=0.062, \chi^{2}=0.081\right]$, the crystal structure of $\mathrm{TiBr}_{2}$-I could only be refined to an $\mathrm{R}_{1}$ of 0.226 by "single crystal" X-ray diffraction [11]. However, Ti-Ti distances in the [ $\left.\mathrm{Ti}_{3}\right]$ triangles of $\mathrm{TiBr}_{2}-\mathrm{I}$ are $300.1(20) \mathrm{pm}$ and thereby somewhat longer than the 292.3(7) pm as observed in $\mathrm{TiBr}_{3}-\mathrm{I}$. This could be interpreted in a way that in $\mathrm{TiBr}_{3}$-I two adjacent $\left[\mathrm{TiBr}_{6}\right]$ octahedra are connected through a common face while in $\mathrm{TiBr}_{2}-\mathrm{I}$ three adjacent $\left[\mathrm{TiBr}_{6}\right]$ octahedra are connected through three common edges. Therefore, it can be concluded that in both $\mathrm{TiBr}_{2}-\mathrm{I}$ and $\mathrm{TiBr}_{3}-\mathrm{I} \mathrm{Ti}-\mathrm{Ti}$ single bonds are formed at sufficiently low temperatures.

Powder X-ray diffraction data for $\mathrm{TiCl}_{2}$ (Fig. 5) and $\mathrm{TiBr}_{2}$ show the I $\rightarrow$ II phase transition (upon heating) at $640 \mathrm{~K}$ and $450 \mathrm{~K}$ and the II $\rightarrow$ I transition (upon cooling) at $530 \mathrm{~K}$ and $320 \mathrm{~K}$, respectively. Hence, there are rather large hystereses of 110 and $130 \mathrm{~K}$ observed for the chloride and bromide, respectively.

Figure 5. Powder X-ray diffraction data for $\mathrm{TiCl}_{2}$ dependent upon temperature; left: heating, right: cooling modes. 
Magnetic measurements show the I $\rightarrow$ II phase transition for $\mathrm{TiI}_{2}$ (upon heating) starting at $240 \mathrm{~K}$ and finished at $280 \mathrm{~K}$ (judging from the effective magnetic moment $\mu_{\mathrm{eff}}$ ) and the II $\rightarrow$ I transition (upon cooling) beginning at $180 \mathrm{~K}$ and finished at $140 \mathrm{~K}$ (Fig. 6). Hence, the width of the hystereses is about $100 \mathrm{~K}$. Note that Klemms values of 1942 [2] fit very well the values obtained by us (Fig. 6, right).

Figure 6. Effective magnetic moments $\mu_{\text {eff }}$ versus temperature for $\mathrm{TiCl}_{2}$ (left) and $\mathrm{TiI}_{2}$ (right). O: Klemms data [2].

The transition temperatures increase in the sequence $\mathrm{I} \rightarrow \mathrm{Br} \rightarrow \mathrm{Cl}$ (with increasing "hardness" of the halide lattice) and the widths of the hystereses appear to be almost independent of the halide lattice. If we consider those temperatures alone where the phase transition is completed upon heating and cooling, we observe the following picture:

$\mathrm{TiCl}_{2} \quad 430 \mathrm{~K} / 590 \mathrm{~K}, \Delta=160 \mathrm{~K}$

$\mathrm{TiBr}_{2} \quad 290 \mathrm{~K} / 440 \mathrm{~K}, \Delta=150 \mathrm{~K}$

$\mathrm{TiI}_{2} \quad 140 \mathrm{~K} / 280 \mathrm{~K}, \Delta=140 \mathrm{~K}$

Difference Thermal Analysis (DTA) curves were also recorded for $\mathrm{TiCl}_{2}$ and $\mathrm{TiBr}_{2}$. Transition temperatures (endo-thermic) are 525 and $350 \mathrm{~K}$ upon heating for $\mathrm{TiCl}_{2}$ and $\mathrm{TiBr}_{2}$, respectively, and 600 and $445 \mathrm{~K}$ upon cooling (exothermic effect).

Differential scanning calorimetry (DSC) exhibits an endothermic effect for $\mathrm{TiI}_{2}$ at 270 $\mathrm{K}$ and an exothermic effect at $172 \mathrm{~K}$ upon cooling. The caloric effects are rather small, enthalpies derived therefrom are $0.26 \mathrm{~kJ} / \mathrm{mol}$ upon heating and $0.22 \mathrm{~kJ} / \mathrm{mol}$ upon cooling (Fig. 7).

Fig. 7. Differential scanning calorimetry diagram for $\mathrm{TiI}_{2}$ (heating and cooling rates were 8 $\mathrm{K} / \mathrm{min}$ ).

\section{Ternary halides, $\mathbf{A}_{\mathbf{x}} \mathbf{T i}_{\mathrm{x}} \mathrm{X}_{\mathrm{z}}$}

\subsection{Titanium(III) in isolated octahedra}

In all of the ternary titanium(III) halides with alkali-metal cations, $\mathrm{Ti}^{3+}$ cations occupy octahedral interstices. There is a variety of structures known for $\mathrm{A}_{3}\left[\mathrm{MX}_{6}\right]$ type halides which differ in the orientation of the $\left[\mathrm{MX}_{6}\right]^{3-}$ octahedra relative to each other. Thereby the proper coordination sphere for the $\mathrm{A}^{+}$cation with respect to its size is achieved, see Table 1 .

Table 1. Mean distances $<\mathrm{d}>$ and coordination numbers $[\mathrm{CN}]$ of the cations in $\mathrm{A}_{3}\left[\mathrm{TiCl}_{6}\right]$ type chlorides

\begin{tabular}{lll}
\hline & $\begin{array}{l}<\mathrm{d}>/ \mathrm{pm} \\
\left(\mathrm{Ti}^{3+}-\mathrm{Cl}^{-}\right.\end{array}$ & $\begin{array}{l}<\mathrm{d}>/ \mathrm{pm}[\mathrm{CN}] \\
\left(\mathrm{A}^{+}-\mathrm{Cl}\right)\end{array}$ \\
& ) & \\
\hline $\mathrm{Na}_{3}\left[\mathrm{TiCl}_{6}\right]$ & 243.1 & $307.1[8], 2 \mathrm{x} ; 277.5[6]$ \\
$\mathrm{K}_{3}\left[\mathrm{TiCl}_{6}\right]$ & 242.8 & $321.1[8] ; 325.7[8] ; 348.2$ \\
& & {$[10]$} \\
$\mathrm{Rb}_{3}\left[\mathrm{TiCl}_{6}\right]$ & 243.8 & $334.0[8] ; 337.9[8] ; 365.5$ \\
& & {$[11]$} \\
$\mathrm{Cs}_{3}\left[\mathrm{TiCl}_{6}\right]$ & 243.7 & $353.4[8] ; 348.5[8] ; 377.8$ \\
& & {$[11]$} \\
\hline
\end{tabular}


Figure 9. Projection of the crystal structure of $\mathrm{K}_{3}\left[\mathrm{TiCl}_{6}\right]$ down [010] showing the relative orientation of the $\left[\mathrm{TiCl}_{6}\right]$ octahedra (middle) and the coordination polyhedra around $\mathrm{K} 1, \mathrm{~K} 2$ and $\mathrm{K} 3$.

Figure 10. Projection of the crystal structure of $\mathrm{Cs}_{3}\left[\mathrm{TiCl}_{6}\right]\left(\mathrm{Rb}_{3}\left[\mathrm{TiCl}_{6}\right]\right.$ is isostructural) showing the relative orientation of the $\left[\mathrm{TiCl}_{6}\right]$ octahedra and the coordination polyhedra around $\mathrm{Cs} 1, \mathrm{Cs} 2$ and $\mathrm{Cs} 3$.

Figure 11. Absorption spectrum above) and reciprocal magnetic susceptibility (below) for $\mathrm{Na}_{3}\left[\mathrm{TiCl}_{6}\right]$.

\subsection{Titanium(III) in dimers of octahedra and tetrahedra}

Halides of the general composition $\mathrm{A}_{3} \mathrm{Ti}_{2} \mathrm{X}_{9}$ contain dimers $\left[\mathrm{Ti}_{2} \mathrm{X}_{9}\right]^{3-}$ which consist of two octahedra sharing one common face, see Fig. 12.

Figure 12. The $\left[\mathrm{Ti}_{2} \mathrm{Cl}_{9}\right]^{3-}$ double octahedron in the crystal structure of $\mathrm{A}_{3} \mathrm{Ti}_{2} \mathrm{X}_{9}$ type halides.

Many trivalent cations throughout the periodic table form these dimers and there is a small number of structure types of which the $\mathrm{Cs}_{3} \mathrm{Cr}_{2} \mathrm{Cl}_{9}$ and the $\mathrm{Cs}_{3} \mathrm{Tl}_{2} \mathrm{Cl}_{9}$ types of structure are the most abundant, see for example [18]. The $\mathrm{A}_{3} \mathrm{Ti}_{2} \mathrm{X}_{9}$ type halides of titanium(III) belong to the $\mathrm{Cs}_{3} \mathrm{Cr}_{2} \mathrm{Cl}_{9}$ type of structure [19], $\mathrm{K}_{3} \mathrm{Ti}_{2} \mathrm{Cl}_{9}$ to a lower symmetry variant known as the $\mathrm{K}_{3} \mathrm{~W}_{2} \mathrm{Cl}_{9}$ type [20]. They may be derived from a ABACBC stacking of closest-packed $\mathrm{CsCl}_{3}$ layers between which two thirds of the available octahedral interstices are occupied such that confacial double octahedra occur which are isolated from each other. The alkali-metal cations are in cuboctahedral and anti-cuboctahedral surrounding, see Fig. 13. 
Figure 13. Crystal structure of the $\mathrm{Cs}_{3} \mathrm{Cr}_{2} \mathrm{Cl}_{9}$ type $\mathrm{A}_{3}\left[\mathrm{Ti}_{2} \mathrm{X}_{9}\right]$ halides; projection of the crystal structure (left) and the cuboctahedral and anti-cuboctahedral surrounding of the two symmetrically independent $\mathrm{A}^{+}$cations (right).

Important structural parameters, distances and angles, within the $\left[\mathrm{Ti}_{2} \mathrm{X}_{9}\right]^{3-}$ dimers are summarized in Table 2. These show, of course, that the Ti-Ti distances grow with increasing sizes of $\mathrm{A}^{+}$and $\mathrm{X}^{-}$. The distances to the terminal halide ions $\left(\mathrm{X}_{\mathrm{t}}\right)$ are always shorter than to the bridging ligands $\left(X_{b}\right), d_{1} / d_{2}>1$. The angles $\alpha$ " and $\beta$ (Fig. 12) lie within a narrow range for the titanium(III) dimers with $\alpha$ " always larger than $\beta$ with small decreases and increases, respectively, with increasing $\mathrm{A}^{+}$size and almost no differences with increasing $\mathrm{X}^{-}$size. The question whether there are bonding interactions between the $\mathrm{Ti}^{3+}-\mathrm{Ti}^{3+}\left(\mathrm{d}^{1}-\mathrm{d}^{1}\right)$ centres, with distances ranging from $310\left(\mathrm{~K}_{3} \mathrm{Ti}_{2} \mathrm{Cl}_{9}\right)$ to $364 \mathrm{pm}\left(\mathrm{Cs}_{3} \mathrm{Ti}_{2} \mathrm{I}_{9}\right)$ is not easy to answer from crystallographic data alone. However, there is a dramatic decrease in the $\mathrm{M}^{3+}-\mathrm{M}^{3+}$ distance for $\mathrm{Cs}_{3} \mathrm{M}_{2} \mathrm{Cl}_{9}$ from $\mathrm{M}=\mathrm{Sc}(357 \mathrm{pm})$ to $\mathrm{M}=\mathrm{Ti}(322 \mathrm{pm}), 9.8 \%$, hence from a $3 \mathrm{~d}^{0}$ to a $3 \mathrm{~d}^{1}$ electronic configuration. This is certainly significant although not quite as dramatic as the $22.7 \%$ decrease for the $\mathrm{Cs}_{3} \mathrm{M}_{2} \mathrm{I}_{9}$ couple $(\mathrm{M}=\mathrm{Y} \rightarrow \mathrm{Zr})$ where, of course, $4 \mathrm{~d}$ electrons are involved in metal-to-metal bonding [24], see Table 2.

Table 2. $M^{3+}-M^{3+}$ distances, distance ratios $d_{1} / d_{2}, d_{1}=d\left(M-X_{b}\right), d_{2}=d\left(M-X_{t}\right)(b=$ bridging, $\mathrm{t}=$ terminal $)$ and angles $\alpha "\left(\mathrm{X}_{\mathrm{b}}-\mathrm{M}-\mathrm{X}_{\mathrm{b}}\right)$ and $\beta\left(\mathrm{M}-\mathrm{X}_{\mathrm{b}}-\mathrm{M}\right)$, see also Fig. 12. Distances in pm, angles in degrees. Grey shaded: $\mathrm{K}_{3} \mathrm{~W}_{2} \mathrm{Cl}_{9}$ type, space group $\mathrm{P}_{3} / \mathrm{m}$; all the others: $\mathrm{Cs}_{3} \mathrm{Cr}_{2} \mathrm{Cl}_{9}$ type, $\mathrm{P} 6_{3} / \mathrm{mmc}$.

\begin{tabular}{llllll}
\hline & $\mathrm{d}(\mathrm{Ti}-\mathrm{Ti})$ & $\mathrm{d}_{1} / \mathrm{d}_{2}$ & $\alpha$ & $\beta$ & Ref. \\
\hline $\mathrm{K}_{3} \mathrm{Ti}_{2} \mathrm{Cl}_{9}$ & 310.5 & 1.066 & 85.4 & 76.9 & 11 \\
& 309.9 & 1.067 & 85.7 & 76.5 & 21 \\
$\mathrm{Rb}_{3} \mathrm{Ti}_{2} \mathrm{Cl}_{9}$ & 314.6 & 1.073 & 84.9 & 77.6 & 16 \\
$\mathrm{Cs}_{3} \mathrm{Ti}_{2} \mathrm{Cl}_{9}$ & 321.5 & 1.075 & 83.8 & 79.1 & 22 \\
$\mathrm{~K}_{3} \mathrm{Ti}_{2} \mathrm{Br}_{9}$ & 328.2 & 1.067 & 85.7 & 76.5 & 21 \\
$\mathrm{Rb}_{3} \mathrm{Ti}_{2} \mathrm{Br}_{9}$ & 335.4 & 1.069 & 84.9 & 77.6 & 21 \\
& 336.6 & 1.070 & 84.7 & 77.8 & 16 \\
$\mathrm{Cs}_{3} \mathrm{Ti}_{2} \mathrm{Br}_{9}$ & 343.4 & 1.074 & 83.8 & 79.0 & 20 \\
& 345.1 & 1.074 & 83.7 & 79.5 & 16
\end{tabular}

\begin{tabular}{llllll}
$\mathrm{Cs}_{3} \mathrm{Sc}_{2} \mathrm{I}_{9}$ & & & & & 23 \\
$\mathrm{Cs}_{3} \mathrm{Ti}_{2} \mathrm{I}_{9}$ & 363.6 & 1.060 & 84.4 & 77.7 & 21 \\
$\mathrm{Cs}_{3} \mathrm{Y}_{2} \mathrm{I}_{9}$ & 405.2 & 1.078 & 82.5 & 93.9 & 24 \\
$\mathrm{Cs}_{3} \mathrm{Zr}_{2} \mathrm{I}_{9}$ & 312.9 & 1.016 & 93.9 & 64.9 & 24 \\
& & & & & \\
$\mathrm{Cs}_{3} \mathrm{Sc}_{2} \mathrm{Cl}_{9}$ & 356.8 & 1.047 & 79.4 & 84.8 & 25 \\
$\mathrm{Cs}_{3} \mathrm{Ti}_{2} \mathrm{Cl}_{9}$ & 321.5 & 1.075 & 83.8 & 79.1 & 22 \\
$\mathrm{Cs}_{3} \mathrm{~V}_{2} \mathrm{Cl}_{9}$ & 327.7 & 1.052 & 93.7 & 80.0 & 16 \\
$\mathrm{Cs}_{3} \mathrm{Cr}_{2} \mathrm{Cl}_{9}$ & 316.7 & 1.070 & 82.7 & 90.5 & 21 \\
\hline
\end{tabular}

$\left[\mathrm{Ti}_{2} \mathrm{X}_{9}\right]^{3-}$ dimers are also present in $\mathrm{CsTi}_{2} \mathrm{Cl}_{7}$-II [27] which are, however, further connected via edges to chains, see Fig. 14. The structure can be understood in terms of ABAC stacking of, alternately, $\mathrm{CsCl}_{3}$ and $\mathrm{Cl}_{4}$ layers with $\mathrm{Ti}^{\mathrm{III}}$ occupying one quarter of the octahedral holes (Fig. 14, left). There is a second modification which was discovered first, $\mathrm{CsTi}_{2} \mathrm{Cl}_{7}-\mathrm{I}$ [28], where $\left[\mathrm{TiCl}_{6}\right]$ octahedra share common edges and vertices. The $\mathrm{Ti}-\mathrm{Ti}$ 
distance through the common face in $\mathrm{CsTi}_{2} \mathrm{Cl}_{7}-\mathrm{II}$ is $322.6 \mathrm{pm}$, much the same as in $\mathrm{Cs}_{3} \mathrm{Ti}_{2} \mathrm{Cl}_{9}$ (321.5 pm), see above. Distances through the common edges are 347.2 and $357.0 \mathrm{pm}$ in II and $\mathrm{I}$, respectively. Keeping the Ti-Ti distance differences in mind, it is not surprising that the $3 \mathrm{~d}^{1}-3 \mathrm{~d}^{1}$ interactions are much more pronounced through the common face in II than through the common edges, about 16 times as much as the interpretation of magnetic susceptibility measurements exhibited, see Fig. 15.

Figure 14. Projections of the crystal structures of $\mathrm{CsTi}_{2} \mathrm{Cl}_{7}-\mathrm{II}$ (left) and -I (right).

Figure 15. Temperature dependence of the molar magnetic susceptibility $\chi$ of $\mathrm{CsTi}_{2} \mathrm{Cl}_{7}-\mathrm{II}$ (insert: $1 / \chi$; squares and circles represent different fields, 5 and $10 \mathrm{kOe}$, respectively; solid and dashed lines two model calculations, see [27]).

In contrast to $\mathrm{CsTi}_{2} \mathrm{Cl}_{7}$ where $\mathrm{Ti}^{\mathrm{iII}}$ resides in octaehedral interstices, the rather rare tetrahedral coordination is observed for $\mathrm{Ti}^{\mathrm{III}}$ in $\mathrm{CsTi}_{2} \mathrm{I}_{7}$ [29]. Two tetrahedra share one common vertex just as in $\mathrm{Cl}_{2} \mathrm{O}_{7}$, Fig. 16. $\mathrm{Ti}^{3+}-\mathrm{I}^{-}$distances are around $251 \mathrm{pm}$ for the terminal iodide ions and $262 \mathrm{pm}$ for the bridging ones. As compared to the octahedral coordination in the $\left[\mathrm{Ti}_{2} \mathrm{I}_{9}\right]^{3-}$ double octahedra, there is a roughly $10 \%$ distance reduction for the tetrahedral coordination in $\left[\mathrm{Ti}_{2} \mathrm{I}_{7}\right]^{-}$.

Figure 16. Projection of the crystal structure of $\mathrm{CsTi}_{2} \mathrm{I}_{7}$ exhibting $\mathrm{TiI}_{4}$ tetrahedra sharing a common vertex to two symmetrically independent $\left[\mathrm{Ti}_{2} \mathrm{I}_{7}\right]^{-}$dimers (right).

\subsection{Mixed-valent titanium(II, III) halides}

Open trimers of octahedra sharing two common faces are present in $\mathrm{K}_{4} \mathrm{Ti}_{3} \mathrm{Br}_{12}$ [30] and $\mathrm{In}_{4} \mathrm{Ti}_{3} \mathrm{Br}_{12}$ [31]. The structures are very similar and show $\mathrm{Ti}-\mathrm{Ti}$ distances through the shared faces of 320 and $309 \mathrm{pm}$, respectively. These bromides must be mixed-valent according to $\mathrm{Ti}^{3+}-\mathrm{Ti}^{2+}-\mathrm{Ti}^{3+}$. Hence, there are four electrons for this open trimer which may lead to bonding interactions. Indeed, strong antiferro-magnetic coupling is seen for $\operatorname{In}_{4} \mathrm{Ti}_{3} \mathrm{Br}_{12}$ [31].

Edge-sharing $\left[\mathrm{TiCl}_{6}\right]^{3-}$ octahedra are present in a second mixed-valent Ti(II, III) compound, $\mathrm{Na}_{5} \mathrm{Ti}_{3} \mathrm{Cl}_{12}$ [32]. It contains chains of [ $\left.\mathrm{TiCl}_{6}\right]$ octahedra sharing trans edges according to $\left[\mathrm{TiCl}_{2 / 1} \mathrm{Cl}_{4 / 2}\right]^{-}$, Fig. 17. $\mathrm{Na}_{5} \mathrm{Ti}_{3} \mathrm{Cl}_{12}$ is isostructural with a number of dysprosium and thulium bromides and iodides, $\mathrm{A}_{5} \mathrm{M}_{3} \mathrm{Br}_{12}$ and $\mathrm{K}_{5} \mathrm{M}_{3} \mathrm{I}_{12}$ with $\mathrm{A}=\mathrm{K}, \mathrm{Rb}$ and $\mathrm{M}=\mathrm{Dy}, \mathrm{Tm}$ [33].

For an isolated trimer according to the formula $\left[\mathrm{Ti}_{3} \mathrm{Cl}_{12}\right]^{5-}$ the titanium atoms would have the charges $+2,+3$ and +2 , the opposite as in $\mathrm{K}_{4} \mathrm{Ti}_{3} \mathrm{Br}_{12}$. However, it is not possible to distinguish between the three titanium atoms as they are incorporated in infinite chains and are crystallographically all equal. Therefore, as for the corresponding dysprosium and thulium bromides and iodides, there are 1.67 electrons per titanium atom in $\mathrm{Na}_{5} \mathrm{Ti}_{3} \mathrm{Cl}_{12}$ and magnetic interactions within the chains are expected as well as three-dimensional ordering at low temperatures.

Figure 17. Projection of the crystal structure of $\mathrm{Na}_{5} \mathrm{Ti}_{3} \mathrm{Cl}_{12}$ exhibiting $\left[\mathrm{TiCl}_{2 / 1} \mathrm{Cl}_{4 / 2}\right]^{-}$chains which are isolated from each other.

An alternative to the infinite chains as observed in $\mathrm{Na}_{5} \mathrm{Ti}_{3} \mathrm{Cl}_{12}$ are oligomers of which only the $\left\{\mathrm{Ti}_{3}\right\}$ variant has been observed so far in $\mathrm{KTi}_{4} \mathrm{Cl}_{11}$ [34] (Fig. 18), but see for the square planar $\left[\left\{\mathrm{OTi}_{4}\right\} \mathrm{I}_{12}\right]^{4-}$ below. $\mathrm{KTi}_{4} \mathrm{Cl}_{11}$ is mixed-valent according to $\mathrm{K}\left(\mathrm{Ti}^{4+}\right)\left\{\left(\mathrm{Ti}^{2+}\right)_{3}\right\}\left(\mathrm{Cl}^{-}\right.$ 
)$_{11}$. Six electrons are available for three $\sigma$ bonds within the $\left\{\mathrm{Ti}_{3}\right\}$ triangular clusters. The TiTi distances are, on the average, $295.5 \mathrm{pm}$ which is very similar to what is observed in $\mathrm{Ti}_{7} \mathrm{Cl}_{16}$ $=\left(\mathrm{Ti}^{4+}\right)\left\{\left(\mathrm{Ti}^{2+}\right)_{3}\right\}_{2}\left(\mathrm{Cl}^{-}\right)_{16}[35], \mathrm{d}=295 \mathrm{pm}$, and to low-temperature $\mathrm{TiBr}_{2}, \mathrm{~d}=$ 292.3(7) $\mathrm{pm}$, see above.

Figure 18. Projection of the crystal structure of $\mathrm{KTi}_{4} \mathrm{Cl}_{11}=\mathrm{KTi}\left\{\mathrm{Ti}_{3}\right\} \mathrm{Cl}_{11}$ exhibiting triangular six-electron titanium clusters.

\subsection{Titanium(II) in trimers and in edge- and face-sharing chains}

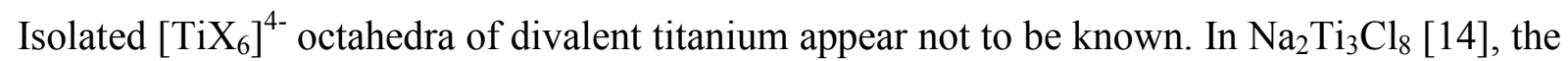
same trimers occur as in $\mathrm{TiCl}_{2}$ at low temperatures, in $\mathrm{Ti}_{7} \mathrm{Cl}_{16}$ and in $\mathrm{KTi}_{4} \mathrm{Cl}_{11}$. There is a phase transition which is driven by much the same forces as for the phase transition in $\mathrm{TiX}_{2}$. At ambient temperature, the $\mathrm{Ti}^{2+}-\mathrm{Ti}^{2+}$ distances are all equal, at $372 \mathrm{pm}$. Triangular clusters are formed at decreasing temperature, the corresponding distances become unequal, 300 and $400 \mathrm{pm}$, respectively, see Fig. 19. There is a considerable volume decrease associated with the phase transition, at $183 \mathrm{~K}$ it is by $9 \%$ smaller than at ambient temperature.

Figure 19. Projection of the crystal structure of $\mathrm{Na}_{2} \mathrm{Ti}_{3} \mathrm{Cl}_{8}-\mathrm{I}$ at $183 \mathrm{~K}$ with the corresponding $\left\{\mathrm{Ti}_{3}\right\} \mathrm{Cl}_{13}$ units.

Calculations of the density of states (DOS) for $\mathrm{Na}_{2} \mathrm{Ti}_{3} \mathrm{Cl}_{8}-\mathrm{I}$ show that there are Ti-3d states just below the Fermi level. In a molecular view, these states correspond to three bonding orbitals of almost equal energies, see Fig. 20.

Figure 20. Density of states (DOS) as calculated for $\mathrm{Na}_{2} \mathrm{Ti}_{3} \mathrm{Cl}_{8}-\mathrm{I}$ and the three energetically almost equal bonding orbitals.

The magnetic moment per $\mathrm{Ti}^{\mathrm{II}}$ in $\mathrm{Na}_{2} \mathrm{Ti}_{3} \mathrm{Cl}_{8}$ drops considerably around the phase transition and exhibits a pronounced hysteresis, see Fig. 21. At sufficiently high temperatures, the magnetic moment of $\mathrm{Na}_{2} \mathrm{Ti}_{3} \mathrm{Cl}_{8}$-II corresponds very well with that of $\mathrm{Na}_{2} \mathrm{TiCl}_{4}$. Hence, we then assume $\left[\mathrm{TiCl}_{6}\right]$ octahedra with $\mathrm{Ti}^{\mathrm{II}}$ centres which do not interact magnetically. In $\mathrm{Na}_{2} \mathrm{TiCl}_{4}$, $\left[\mathrm{TiCl}_{6}\right]$ octahedra share common edges to chains (Fig. 22), with $\mathrm{Ti}^{2+}-\mathrm{Ti}^{2+}$ distances of $385.6 \mathrm{pm}$ [36]. Below $13 \mathrm{~K}$, magnetic superstructure reflections in a neutron diffraction experiment account for the onset of a three-dimensional antiferromagnetic ordering [37].

Figure 21. Magnetic moment $\mu_{\text {eff }}$ versus temperature for $\mathrm{Na}_{2} \mathrm{Ti}_{3} \mathrm{Cl}_{8}$ and for $\mathrm{Na}_{2} \mathrm{TiCl}_{4}$. The heating curve for $\mathrm{Na}_{2} \mathrm{Ti}_{3} \mathrm{Cl}_{8}$ corresponds to (b), cooling to (a).

Figure 22. Projection of the crystal structure of $\mathrm{Na}_{2} \mathrm{TiCl}_{4}$ (left) and part of the $\left[\mathrm{TiCl}_{2 / 1} \mathrm{Cl}_{4 / 2}\right]^{2-}$ chains of edge-connected octahedra (right).

Infinite chains of $\left[\mathrm{TiX}_{6}\right]$ octahedra are also present in $\mathrm{ATiX}_{3}$ type halides $(\mathrm{A}=\mathrm{K}, \mathrm{Rb}$, $\mathrm{Cs} ; \mathrm{X}=\mathrm{Cl}, \mathrm{Br}, \mathrm{I})$ [38-41]. However, the chains are face-sharing according to $\mathrm{A}\left[\mathrm{TiX}_{6 / 2}\right]$. They crystallize essentially with the $\mathrm{CsNiCl}_{3}$ type of structure, so-called hexagonal perovskite. Thus, $\mathrm{AX}_{3}$ closest-packed layers are stacked in the $\mathrm{AB}$ fashion. One third of all octahedral interstices are occupied, all along the $c$ direction. The structure field map of Fig. 23 shows that when the size ratio of $\mathrm{A}^{+}$to $\mathrm{X}^{-}$becomes unfavourable, there is a symmetry reduction from $\mathrm{P}_{3} / \mathrm{mmc}$ to $\mathrm{P}_{3}$ (or $\mathrm{P}_{3} \mathrm{~cm}$ as reported for $\mathrm{RbTiI}_{3}$ [38]. Fig. 24 shows that in these latter halides the $\left[\mathrm{TiCl}_{6 / 2}\right]$ chains are rotated and shifted against each other. The reason for this is to 
accomodate monovalent cations which are too small to fit into an anti-cuboctahedral surrounding which is, on the other hand, typical for the $\mathrm{CsNiCl}_{3}$-type of structure. $\mathrm{Ti}^{2+}-\mathrm{Ti}^{2+}$ distances are little above $300 \mathrm{pm}$ for the respective chlorides $\mathrm{ATiCl}_{3}$, around 317 in bromides and little below 340 in iodides, see for an overview [41].

Figure 23. Structure field map for $\mathrm{ATiX}_{3}$ type halides exhibiting the $\mathrm{CsNiCl}_{3}$-type highsymmetry halides (squares, $\mathrm{P}_{3} / \mathrm{mmc}$ ) as well as those of lower symmetry as reported for $\mathrm{RbTiI}_{3}\left(\mathrm{P}_{3} \mathrm{~cm}\right)$ and for the $\mathrm{KNiCl}_{3}$ type halides $\left(\mathrm{P}_{3}\right.$, open circles).

Figure 24. Two projections each of the crystal structures of $\mathrm{CsTiCl}_{3}$ (above) and $\mathrm{KTiCl}_{3}$ (below).

\section{Titanium halides with clusters other than dimers and trimers}

With $3 \mathrm{~d}$ elements clusters are rather rare although by no means impossible. For titanium in halides, the trimeric six-electron cluster $\left\{\mathrm{Ti}_{3}\right\}$ appears to be largest cluster when these are considered without endohedral, electron-contributing atoms. An isolated octahedral cluster $\left\{\mathrm{Ti}_{6}\right\}$ would afford 16 electrons for eight $3 \mathrm{c}-2 \mathrm{e}$ bonds. This would only be possible for a composition, for example, $\left\{\mathrm{Ti}_{6}\right\} \mathrm{Cl}_{8}$. Such a sub-chloride is not known. If an analogous structure as for $\left\{\mathrm{Nb}_{6}\right\} \mathrm{Cl}_{14}$ [42], a 16-electron cluster, would be considered, an interstitial contributing four electrons is needed. Indeed, $\left\{\mathrm{CTi}_{6}\right\} \mathrm{Cl}_{14}$ is the first and so far only titanium cluster of that type [43]. It is isostructural with the homologous $\left\{\mathrm{CZr}_{6}\right\} \mathrm{Cl}_{14}$ [44]. $\left\{\mathrm{CTi}_{6}\right\} \mathrm{Cl}_{12}{ }^{\mathrm{i}} \mathrm{Cl}_{6}{ }^{\mathrm{a}}$ cluster complexes (see Fig. 25) are connected according to $\left\{\mathrm{CTi}_{6}\right\} \mathrm{Cl}_{10}{ }^{\mathrm{i}} \mathrm{Cl}_{2 / 2}{ }^{\mathrm{i}-}$ ${ }^{\mathrm{a}} \mathrm{Cl}_{2 / 2}{ }^{\mathrm{a}-\mathrm{i}} \mathrm{Cl}_{4 / 2}{ }^{\mathrm{a}-\mathrm{a}}$ (in the Schäfer-Schnering notation [45]).

Figure 25. The $\left\{\mathrm{CTi}_{6}\right\} \mathrm{Cl}_{12}^{\mathrm{i}} \mathrm{Cl}_{6}^{\mathrm{a}}$ cluster unit in the crystal structure of $\left\{\mathrm{CTi}_{6}\right\} \mathrm{Cl}_{14}$.

Tetranuclear titanium clusters would afford either 10 electrons for a cluster analogous to the planar skite-like cluster as in $\mathrm{Cs}\left[\left\{\mathrm{Nb}_{4}\right\} \mathrm{Cl}_{11}\right]$ [46] or 12 or 8 for a tetrahedron with six $2 \mathrm{c}-2 \mathrm{e}$ (six edges) or four $3 \mathrm{c}-2 \mathrm{e}$ bonds (four faces). Eight electrons would also be possible for a square planar $\left\{\mathrm{Ti}_{4}\right\}$ cluster with four $2 \mathrm{c}-2 \mathrm{e}$ bonds. None of these have been observed. Instead, the isostructural salts $\mathrm{K}_{4}\left[\left\{\mathrm{OTi}_{4}\right\} \mathrm{I}_{12}\right]$ [47] and $\mathrm{Rb}_{4}\left[\left\{\mathrm{OTi}_{4}\right\} \mathrm{I}_{12}\right]$ [48] have been obtained during attempts to grow single crystals of $\mathrm{KTiI}_{3}$ and $\mathrm{RbTiI}_{3}$, apparently with some oxygen contamination. These contain the square-planar oxygen-centered cluster $\left\{\mathrm{OTi}_{4}\right\}$ surrounded by a cuboctahedron of iodide ligands, see Fig. 26.

Figure 26. Projection of the crystal structure of $\mathrm{K}_{4}\left[\left\{\mathrm{OTi}_{4}\right\} \mathrm{I}_{12}\right]$.

In $\mathrm{A}_{4}\left[\left\{\mathrm{OTi}_{4}\right\} \mathrm{I}_{12}\right](\mathrm{A}=\mathrm{K}, \mathrm{Rb})$ there are six electrons available for intra-cluster bonding. These six electrons occupy three low-lying molecular orbitals, see Fig. 27. Band structure calculations and the Crystal Orbital Hamiltonian Populations (COHP) derived therefrom show (Fig. 28) that there is considerable Ti-Ti bonding below the Fermi level as well as (ionic) Ti$\mathrm{O}$ and $\mathrm{Ti}-\mathrm{I}$ bonding. There is, however, some Ti-I bonding antibonding which must be (and is) overcompensated by $\mathrm{Ti}-\mathrm{Ti}$ bonding in the same energy region.

Figure 27. Molecular orbital scheme (left) for the frontier orbitals in the $\left[\left\{\mathrm{OTi}_{4}\right\} \mathrm{I}_{12}\right]^{4-}$ cluster unit in $\mathrm{K}_{4}\left[\left\{\mathrm{OTi}_{4}\right\} \mathrm{I}_{12}\right]$ and graphic representations of these orbitals of which the three lowest in energy are occupied by six electrons.

Figure 28. Crystal Orbital Hamiltonian Population (COHP) analysis for $\mathrm{K}_{4}\left[\left\{\mathrm{OTi}_{4}\right\} \mathrm{I}_{12}\right]$. 


\section{Conclusions}

Titanium as the second transition metal has four valence electrons. In binary and ternary (quaternary) halides, the oxidation states $+4\left(3 \mathrm{~d}^{0}\right),+3\left(3 \mathrm{~d}^{1}\right)$, and $+2\left(3 \mathrm{~d}^{2}\right)$ are known. Of these the $\mathrm{d}^{1}$ and $\mathrm{d}^{2}$ "systems" are the most interesting as they offer spin, charge, and orbital ordering in low-dimensional systems. The tri- and dihalides, $\mathrm{TiX}_{3}$ and $\mathrm{TiX}_{2}(\mathrm{X}=\mathrm{Cl}, \mathrm{Br}, \mathrm{I})$, are the simplest of such $\mathrm{d}^{1}$ and $\mathrm{d}^{2}$ systems and they are paramagnetic at sufficiently high temperatures, and undergo one- and two-dimensional Peierls distortions upon cooling. In the language of the chemist, they form $\sigma$-bonded dimers $\left\{\mathrm{Ti}_{2}\right\}$ in $\mathrm{TiX}_{3}$ and trimers $\left\{\mathrm{Ti}_{3}\right\}$ in $\mathrm{TiX}_{2}$. The formation of $\left\{\mathrm{CTi}_{6}\right\} \mathrm{Cl}_{14}$ might be regarded as a three-dimensional Peierls distortion although a single carbon atom is needed to secure a 14-electron octahedral cluster. One- and two-dimensional systems are also seen in ternary halides such as $\mathrm{ATiX}_{3}$ (chains of facesharing $\left[\mathrm{TiX}_{6}\right]$ octahedra) and $\mathrm{Na}_{2} \mathrm{TiCl}_{4}$ (chains of edge-sharing [ $\left.\mathrm{TiX}_{6}\right]$ octahedra) and in $\mathrm{A}_{3} \mathrm{Ti}_{2} \mathrm{X}_{9}$ (dimers of face-sharing [ $\left.\mathrm{TiX}_{6}\right]$ octahedra) although magnetic interactions occur only in a way which one would not consider as a chemical bond. These are, however, observed in $\mathrm{Na}_{2} \mathrm{Ti}_{3} \mathrm{Cl}_{8}$ and $\mathrm{KTi}_{4} \mathrm{Cl}_{11}$ which both exhibit the same trimers as seen in $\mathrm{TiX}_{2}$ at low temperatures. Clusters are rare in titanium halide chemistry. Except for the dimers and trimers, all the others known need an additional main-group element atom to ensure the right electron count, see $\left\{\mathrm{CTi}_{6}\right\} \mathrm{Cl}_{14}$ and $\mathrm{K}_{4}\left[\left\{\mathrm{OTi}_{4}\right\} \mathrm{I}_{12}\right]$.

\section{Acknowledgements}

This work was supported by the Deutsche Forschungsgemeinschaft, Bonn (Sonderforschungsbereich 608 "Komplexe Übergangsmetall-verbindungen mit Spin- und Ladungsfreiheitsgraden und Unordnung") and by the State of Nordrhein-Westfalen as well as the Universität zu Köln. Chapter 2 has appeared in a similar version (G. Meyer, Th. Gloger, Lower Valent Titanium Halides, in: 20 Jahre Wilhelm-Klemm-Stiftung, Shaker Verlag, Aachen, 2006, p. 105-112.) to honour Professor Wilhelm Klemm and the foundation which bears his name. GM is especially grateful to his co-authors Dr. Thomas Gloger and Dr. Jan Beekhuizen) from whose theses otherwise unpublished results are reported here. We are also grateful to Dr. Dirk Hinz, Dr. Liesbet Jongen and Prof. Dr. Angela Möller who have contributed to the here reported subject over the years as is evident from the references. We are especially grateful to Prof. Dr. Anja-Verena Mudring (Bochum) who has provided much theoretical insight and to Dr. Ingo Pantenburg for continuous help in many ways. This report was first designed during a stay at Iowa State University in March of 2008 and finished during the late and early days of 2008/2009 with much support by Professor John D. Corbett. Thank you, John!

\section{References}

[1] Gmelins Handbuch der Anorganischen Chemie, System-Nr. 41: Titan, 8. Auflage, Verlag Chemie, Weinheim, 1951.

[2] W. Klemm, L. Grimm, Z. Anorg. Allg. Chem. 1942, 249, 198 and 209.

[3] W. Klemm, E. Krose, Z. Anorg. Allg. Chem. 1947, 253, 209.

[4] E. Holze, Dissertation, Universität Münster, 1956.

[5] H. G. von Schnering, Naturwissenschaften 1966, 53, 359.

[6] H. Hillebrecht, Th. Ludwig, G. Thiele, Z. Anorg. Allg. Chem. 2004, 630, 2199, and literature cited therein.

[7] A. Lachgar, D. S. Dudis, J. D. Corbett, Inorg. Chem. 1990, 29, 2242. 
[8] D. Babel, J. Solid State Chem. 1972, 4, 410; H. Hillebrecht, Dissertation, Universität Freiburg, 1991.

[9] K. Brodersen, H.-K. Breitbach, G. Thiele, Z. Anorg. Allg. Chem. 1968, 357, 162; H. Hillebrecht, Dissertation, Universität Freiburg, 1991.

[10] H. Wagner, Dissertation, Universität Erlangen-Nürnberg, 1980.

[11] Th. Gloger, Dissertation, Universität zu Köln, 1998.

[12] J. Angelkort, A. Schönleber, S. van Smaalen, 16th International Conference on Solid Compounds of Transition Elements, Dresden, Germany, 2008, Poster 90; J. Solid State Chem. 2008, doi:10.1016/j.jssc.2008.11.028.

[13] H. G. von Schnering, H. Wöhrle, H. Schäfer, Naturwissenschaften 1961, 48, 159; A. Simon, H. G. von Schnering, J. Less-Common Met. 1966, 11, 31; M. Stroebele, J. Glaser, A. Lachgar, H.-J. Meyer, Z. Anorg. Allg. Chem. 2001, 627, 2002.

[14] D. J. Hinz, G. Meyer, T. Dedecke, W. Urland, Angew. Chem. 1995, 107, 97; Angew. Chem. Int. Ed. Engl. 1995, 34, 71.

[15] D. Hinz, T. Gloger, G. Meyer, Z. Anorg. Allg. Chem. 2000, 626, 822-824.

[16] J. Beekhuizen, Dissertation, Universität zu Köln, 2006.

[17] R. Ameis, S. Kremer, D. Reinen, Inorg. Chem. 1985, 24, 2751.

[18] G. Meyer, Prog. Solid State Chem. 1982, 14, 141-219.

[19] G. J. Wessel, D. J. W. IJdo, Acta Crystallogr. 1957, 10, 466.

[20] W. H. Watson, J. Waser, Acta Crystallogr. 1958, 11, 689.

[21] S. Hartwig, Dissertation, Universität Bayreuth, 2003.

[22] T. Gloger, Hinz, G. Meyer, A. Lachgar Z. Kristallogr. 1996, 211, 821.

[23] G. Meyer, U. Strack, unpublished results (1980); see also: G. Meyer, J. D. Corbett, Inorg. Chem. 1981, 20, 2637-2631.

[24] D. H. Guthrie, G. Meyer, J. D. Corbett, Inorg. Chem. 1981, 20, 1192-1201.

[25] G. Meyer, R. Blachnik, Z. Anorg. Allg. Chem. 1983, 503, 126-132.

[26] B. Leuenberger, B. Briat, J. C. Canil, A. Furrer, P. Fischer, H. U. Güdel, Inorg. Chem. 1986, 25, 2930-2935.

[27] D. Hinz, T. Gloger, A. Möller, G. Meyer, Z. Anorg. Allg. Chem. 2000, 626, 23-27.

[28] J. Zhang, J. D. Corbett, Z. Anorg. Allg. Chem. 1990, 580, 36.

[29] L. Jongen, G. Meyer, Z. Anorg. Allg. Chem. 2004, 630, 211-212.

[30] L. Jongen, G. Meyer, Z. Anorg. Allg. Chem. 2004, 630, 1732.

[31] M. Schroeder, K. Krämer, S. Decurtins, H. Hillebrecht, Z. Kristallogr. 2007, Suppl. 21, 079-53.

[32] D. Hinz, Dissertation, Universität Hannover, 1994.

[33] G. Schilling, M. Böcker, A. Möller, G. Meyer, Z. Anorg. Allg. Chem. 2001, 627, 13091312.

[34] J. Zhang, R-Y. Qi, J. D. Corbett, Inorg. Chem. 1991, 30, 4794-4798.

[35] H. Schäfer, R. Laumann, Z. Anorg. Allg. Chem. 1981, 474, 135; B. Krebs, G. Henkel, Z. Anorg. Allg. Chem. 1981, 474, 149.

[36] D. J. Hinz, T. Dedecke, W. Urland, G. Meyer, Z. Anorg. Allg. Chem. 1994, 620, 801804.

[37] M. Winkelmann, D. Welz, M. Baehr, D. J. Hinz, T. Dedecke, W. Urland, G. Meyer, J. Magn. Magn. Mat. 1995, 140-144, 1667-1668.

[38] H. W. Zandbergen, J. Solid State Chem. 1981, 37, 308;

[39] G. Meyer, U. Packruhn, Z. Anorg. Allg. Chem. 1985, 524, 90;

[40] G. Meyer, D. J. Hinz, U. Floerke, Z. Kristallogr. 1993, 208, 370;

[41] L. Jongen, T. Gloger, J. Beekhuizen, G. Meyer, Z. Anorg. Allg. Chem. 2005, 631, 582586.

[42] A. Simon, H. G. von Schnering, H. Wöhrle, H. Schäfer, Z. Anorg. Allg. Chem. 1965, $339,1555-170$.

[43] D. J. Hinz, G. Meyer, J. Chem. Soc., Chem. Commun. 1994, 125-126.

[44] R. P. Ziebarth, J.D. Corbett, J. Solid State Chem. 1989, 80, 56.

[45] H. Schäfer, H. G. Schnering, Angew. Chem. 1964, 76, 833. 
[46] A. Broll, A. Simon, H. G. von Schnering, H. Schäfer, Z. Anorg. Allg. Chem. 1969, 367,1 .

[47] L. Jongen, A.-V. Mudring, A. Möller, G. Meyer, Angew. Chem. 2004, 116, $3245-$ 3248; Angew. Chem. Int. Ed. 2004, 43, 3183-3185.

[48] L. Jongen, A.-V. Mudring, G. Meyer, Z. Kristallogr. 2004, Suppl. 21, 166.

Received: ((will be filled in by the editorial staff))
Published online: ((will be filled in by the editorial staff)) 


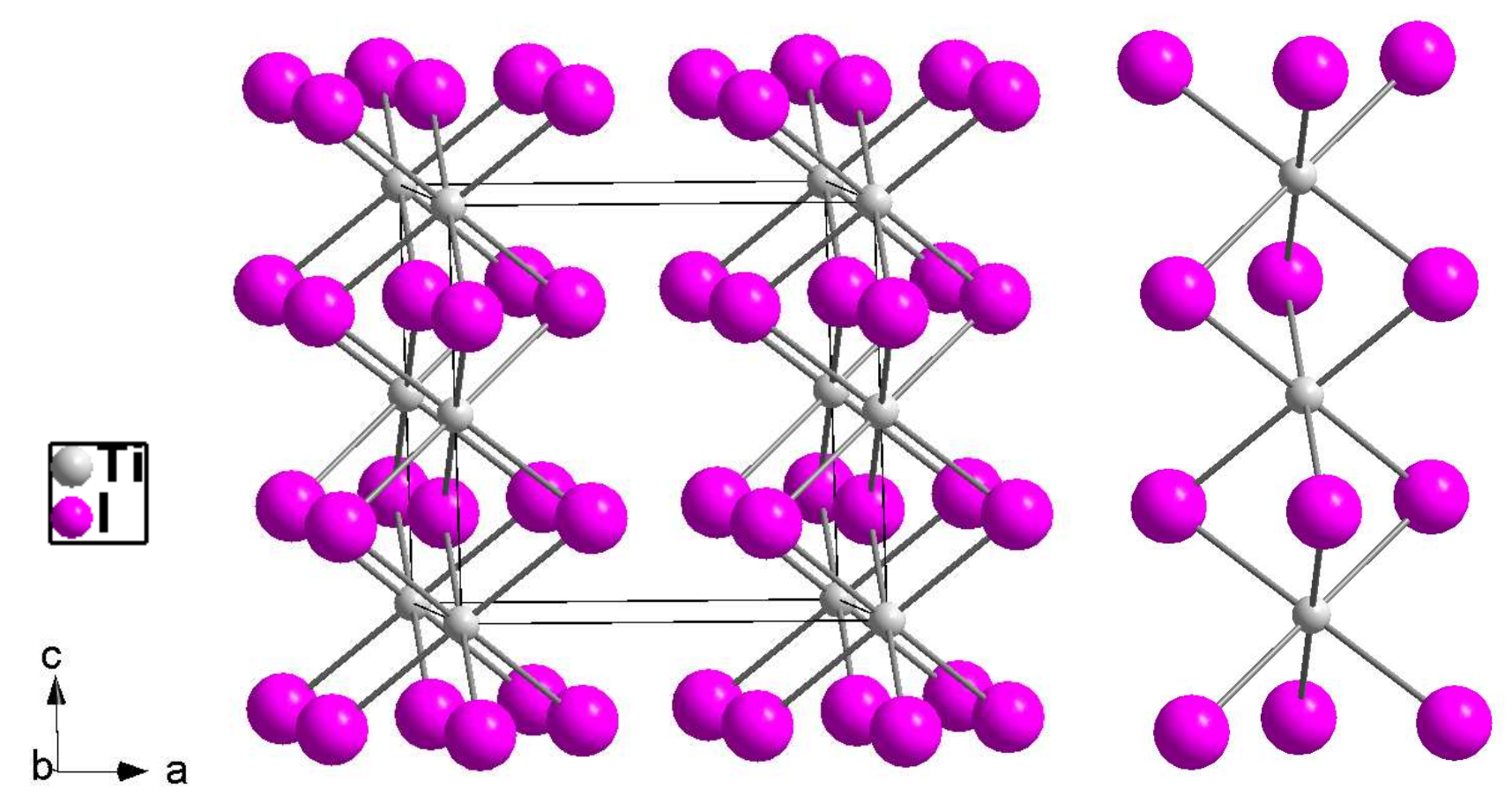

Figure 1 


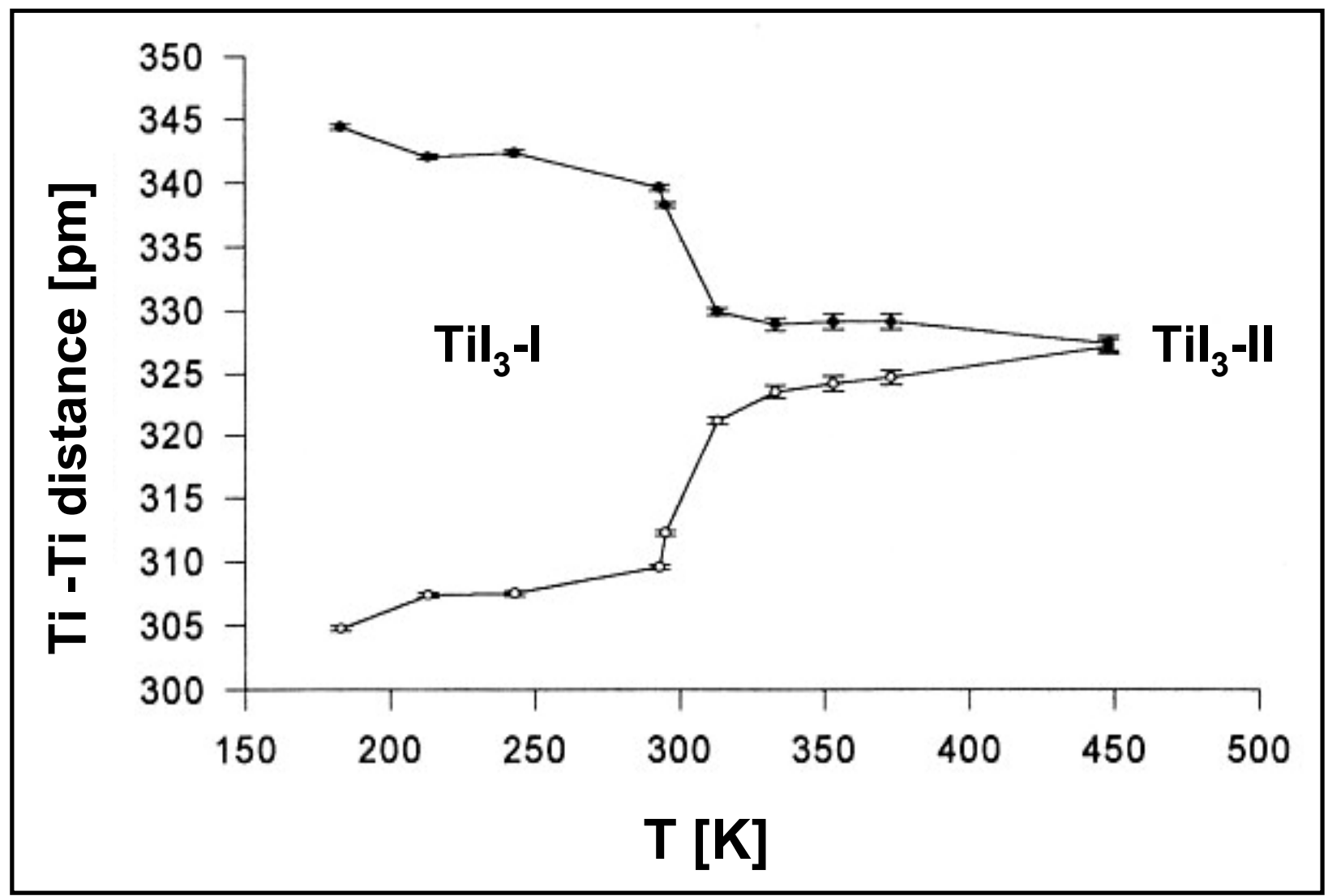

Figure 2 

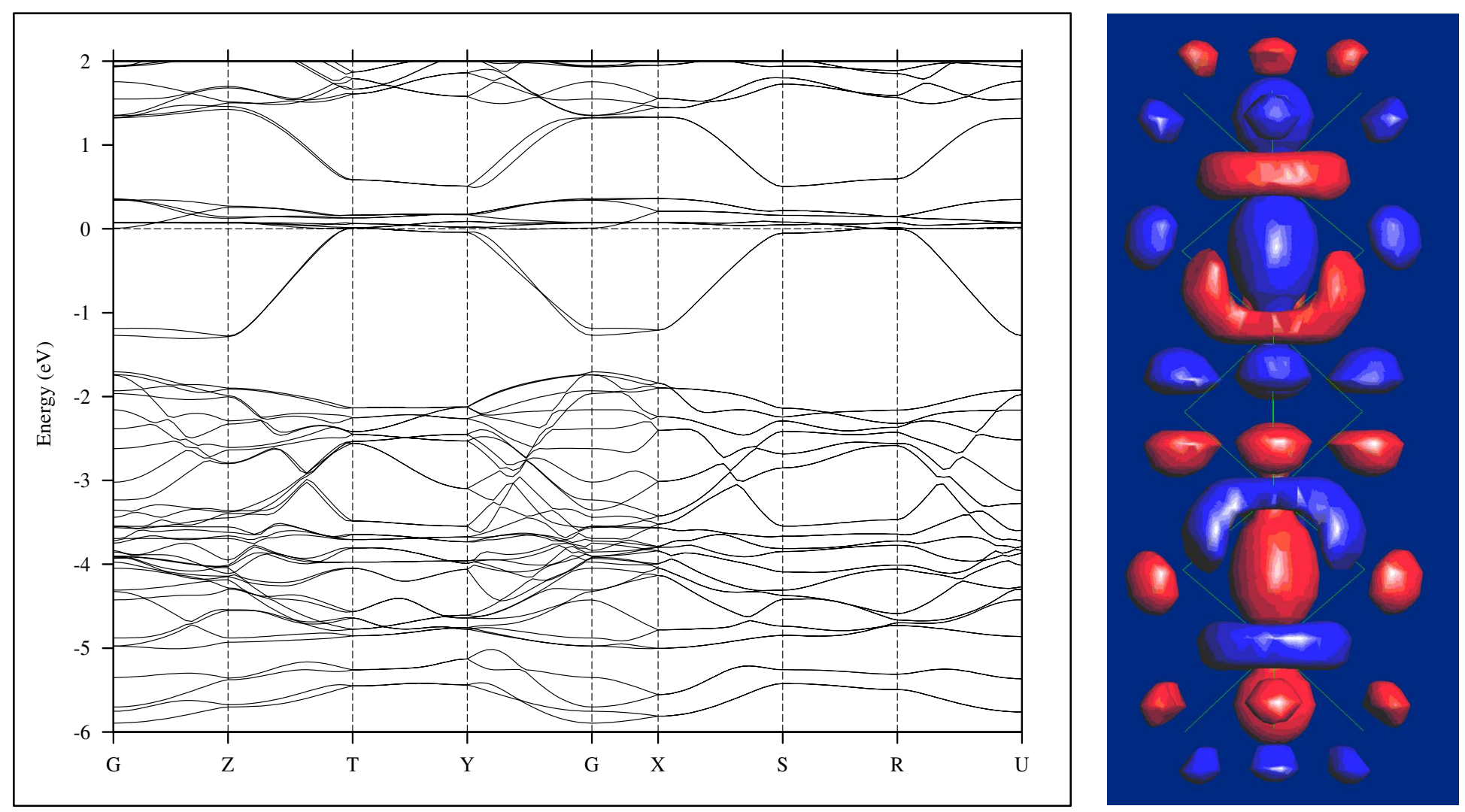

Figure 3 

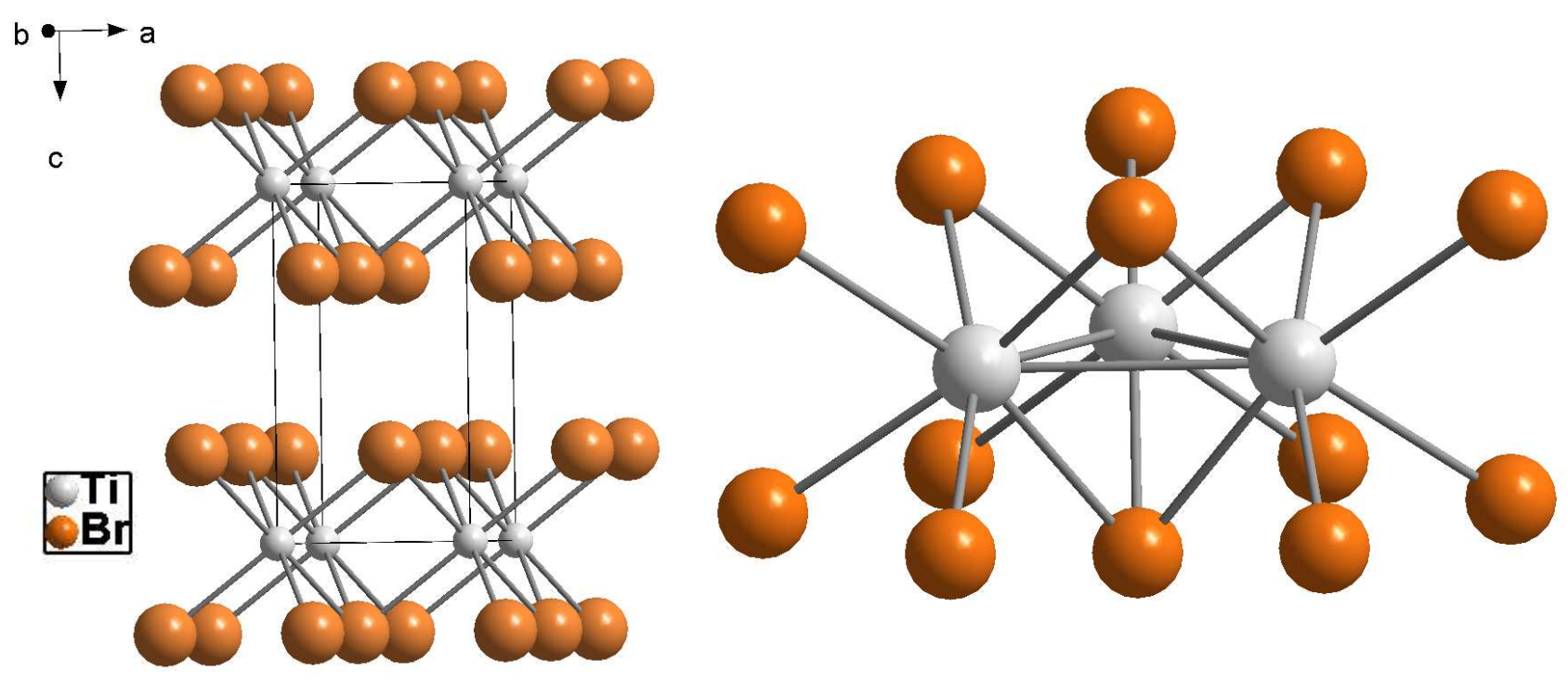

\section{Figure 4}



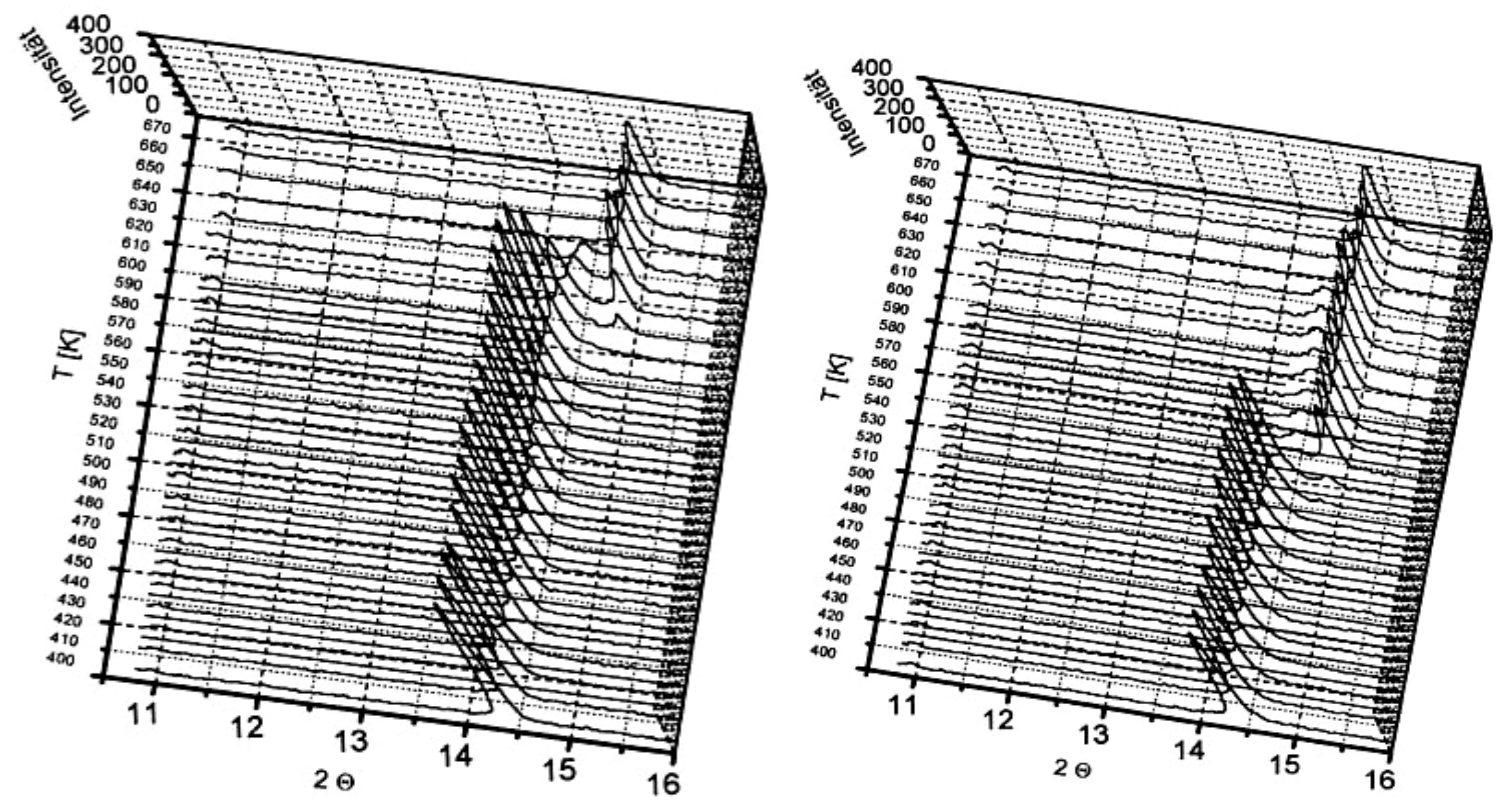

Figure 5 

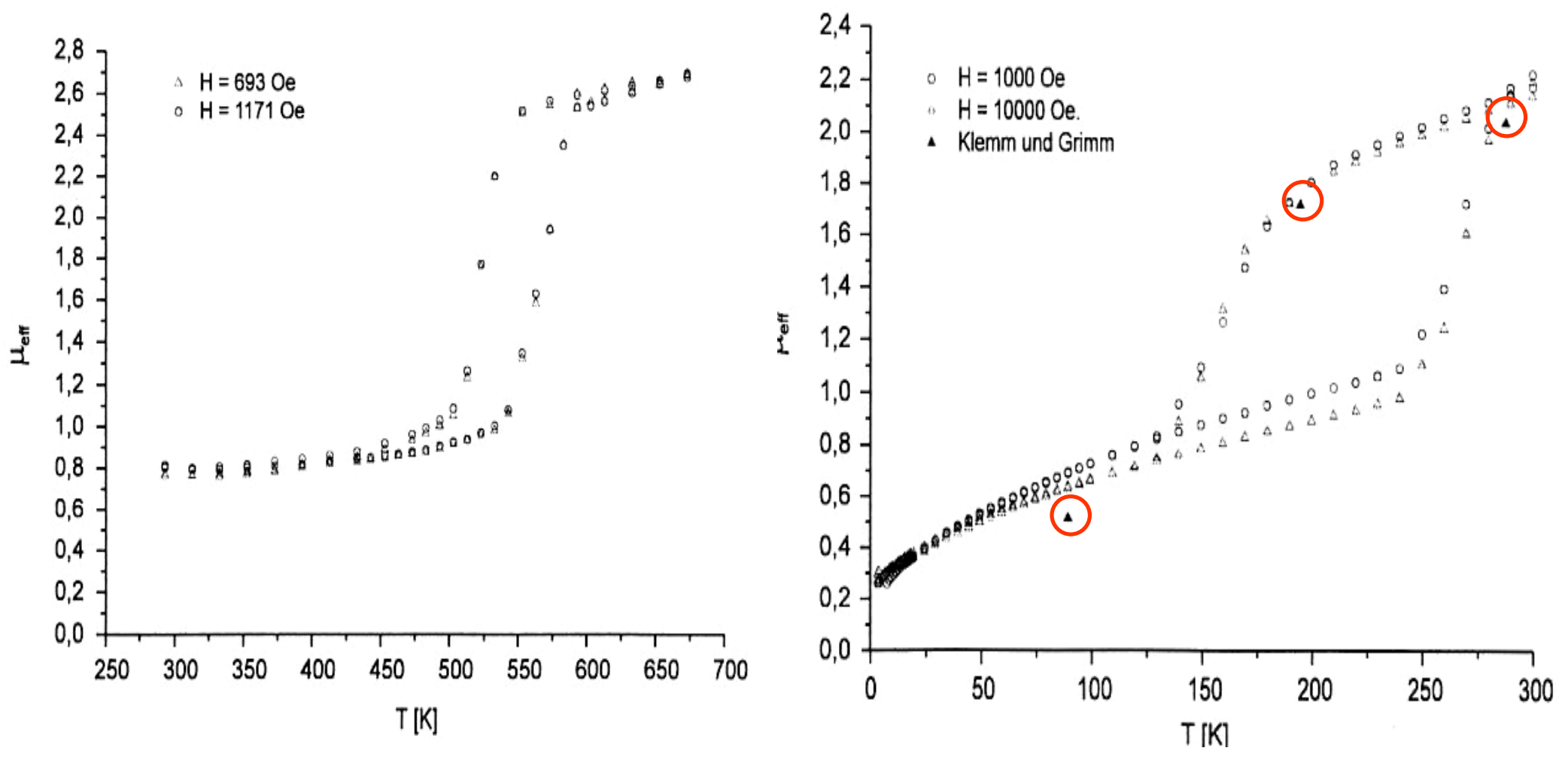

Figure 6 


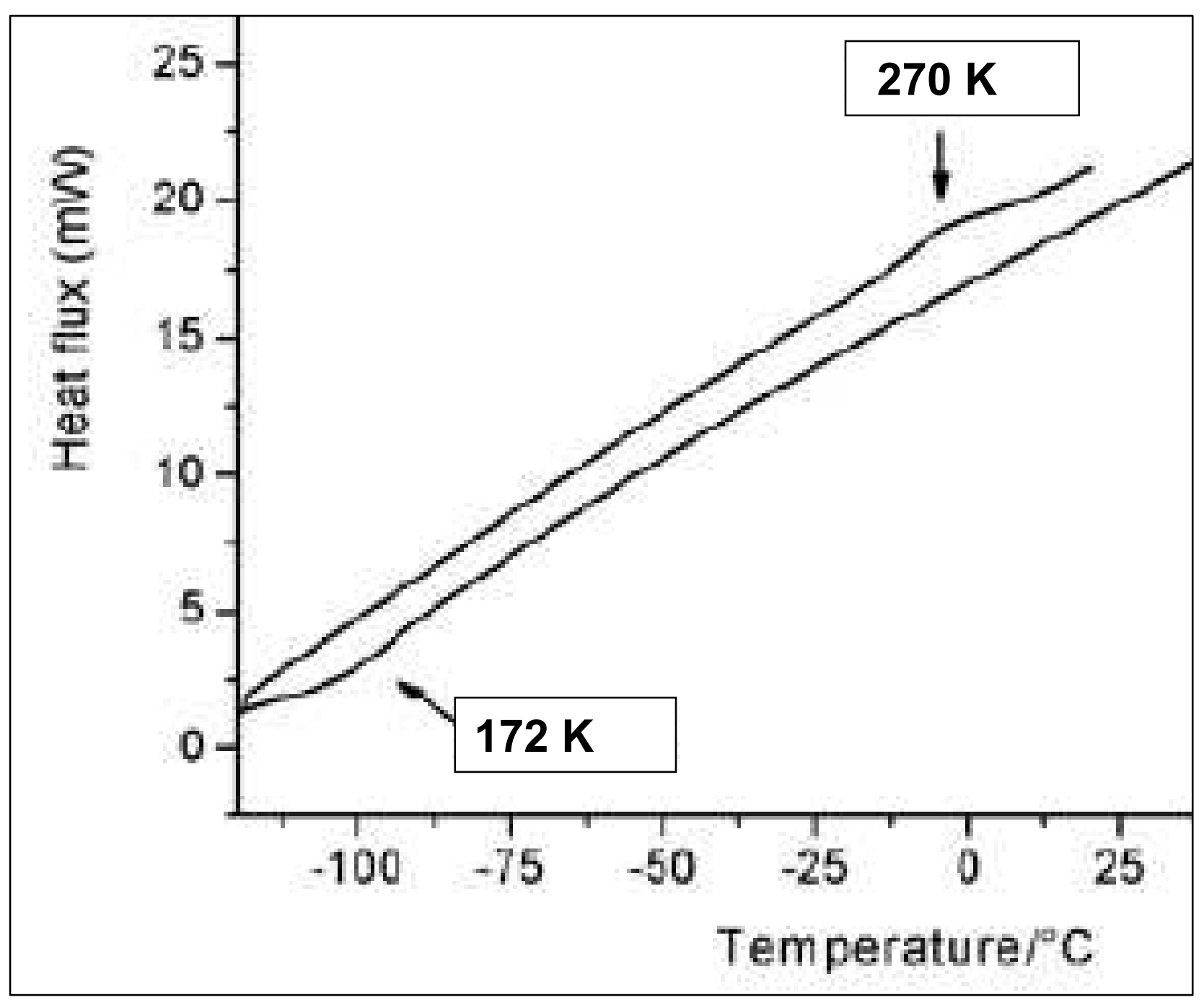

Figure 7 

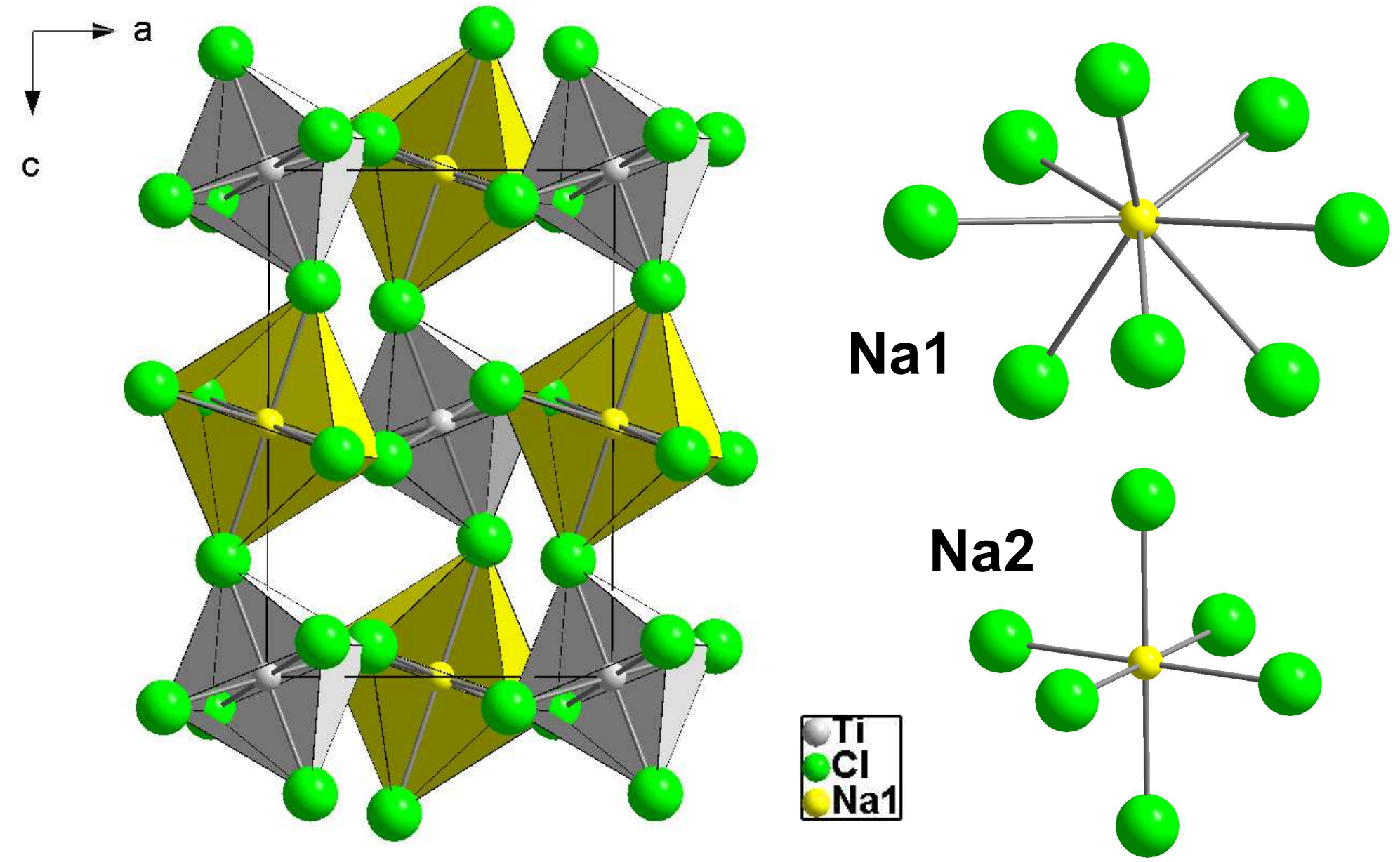

Figure 8

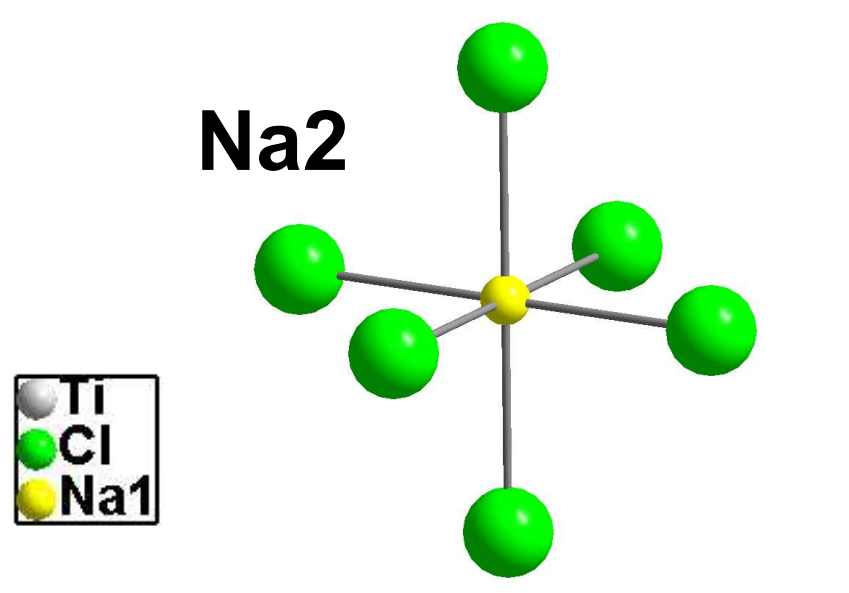



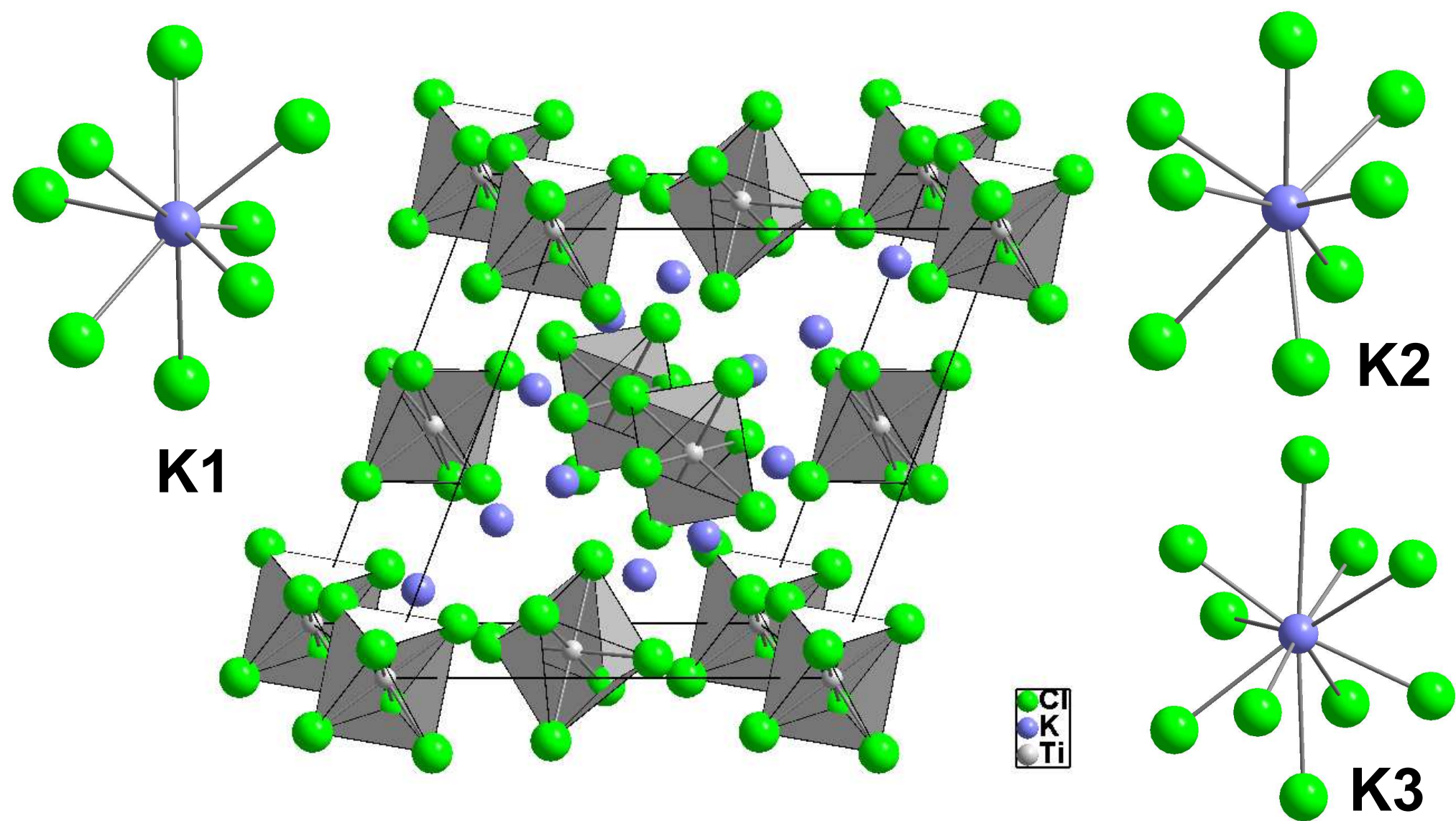

Figure 9 

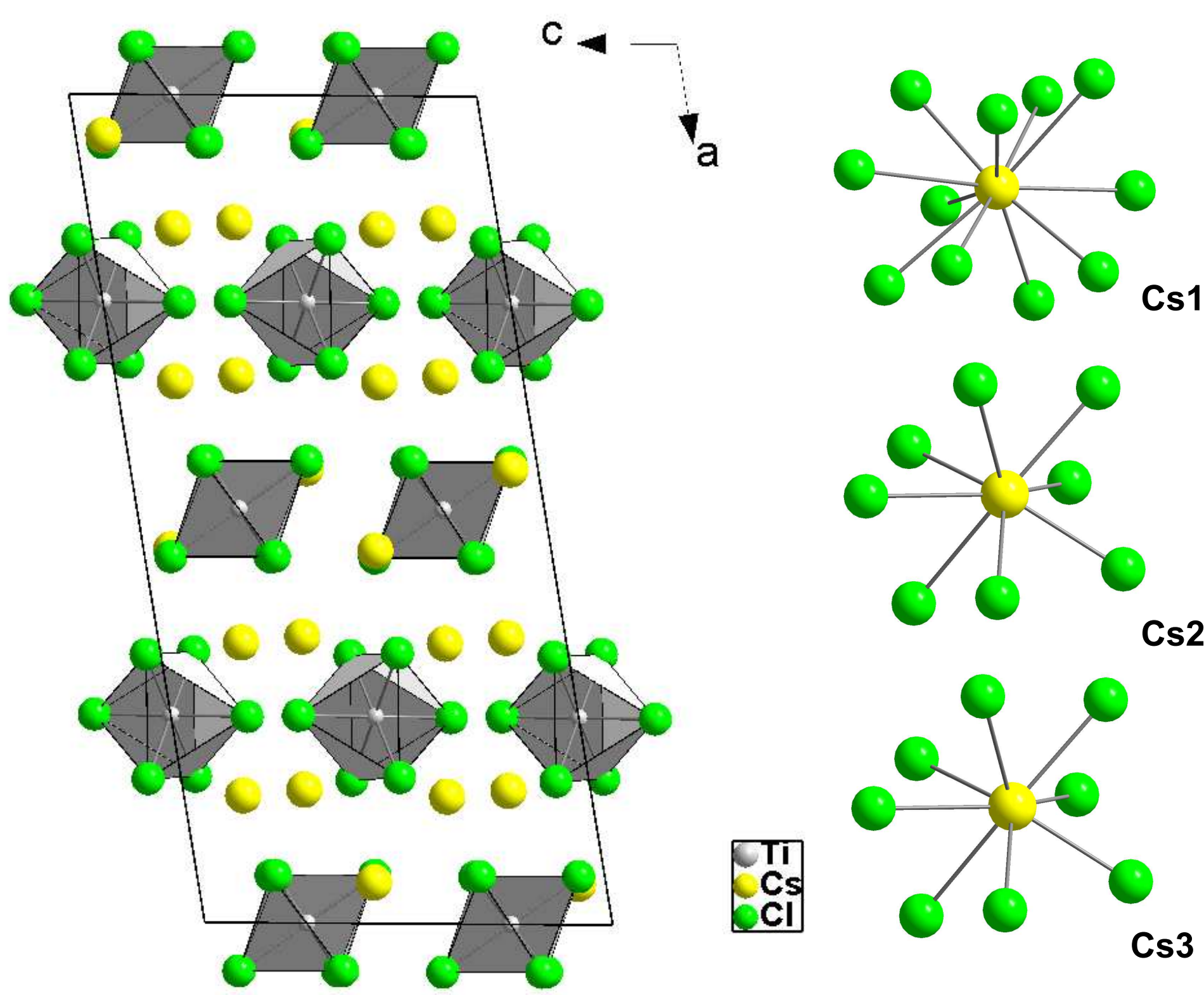

Figure 10 


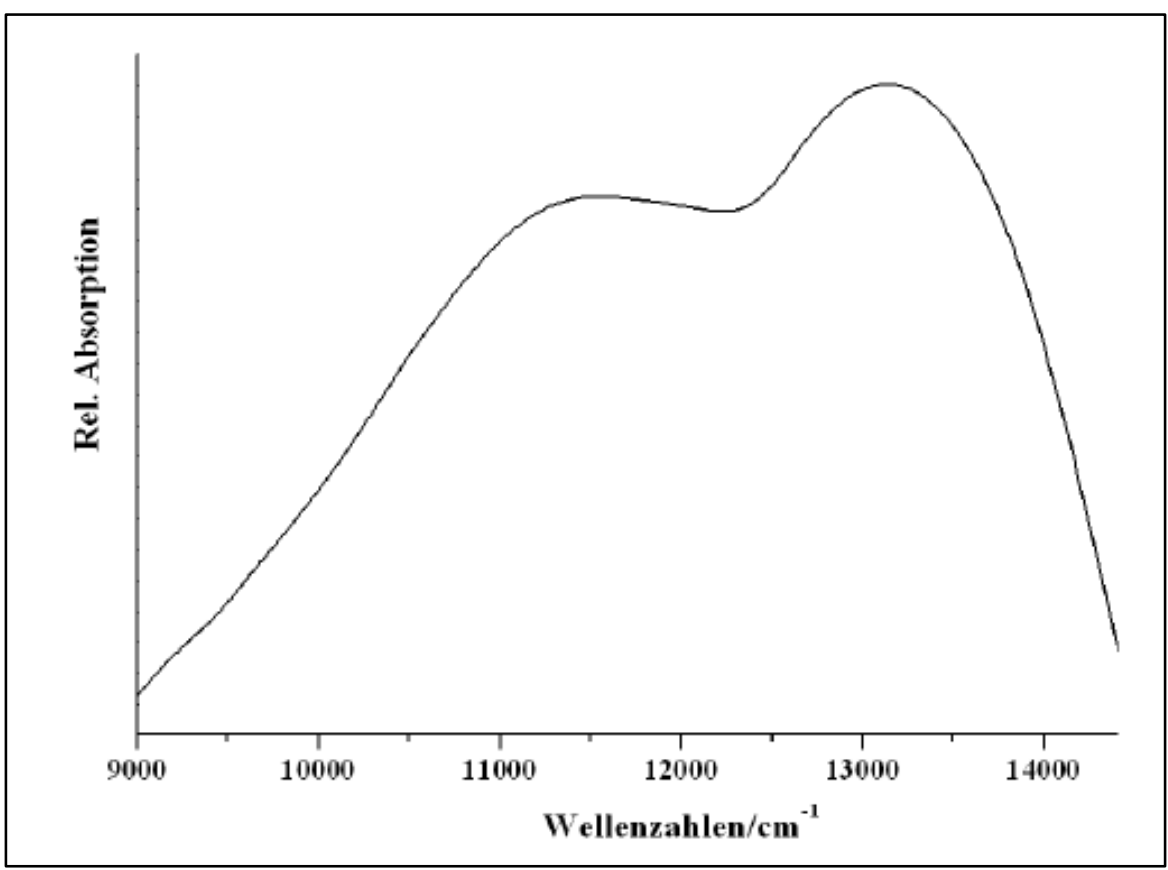

Figure 11

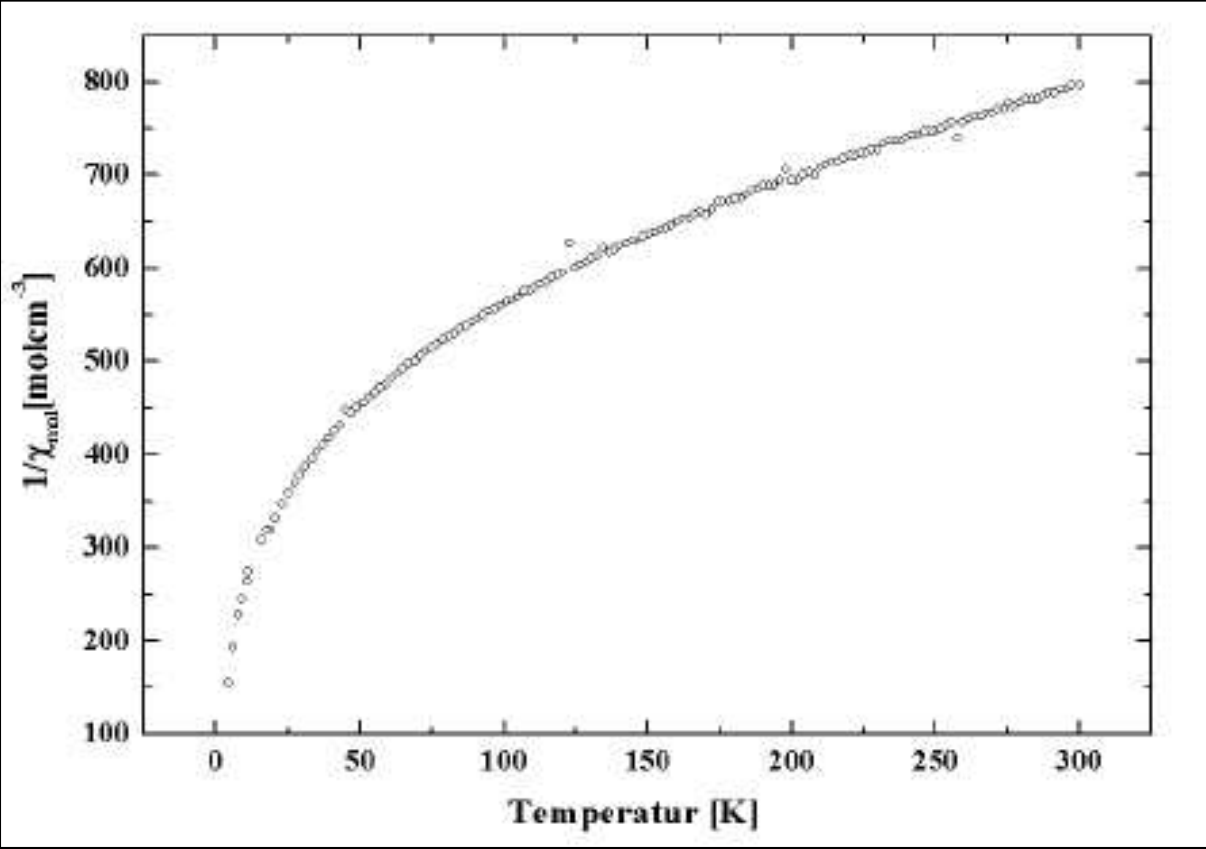

Wiley-VCH 


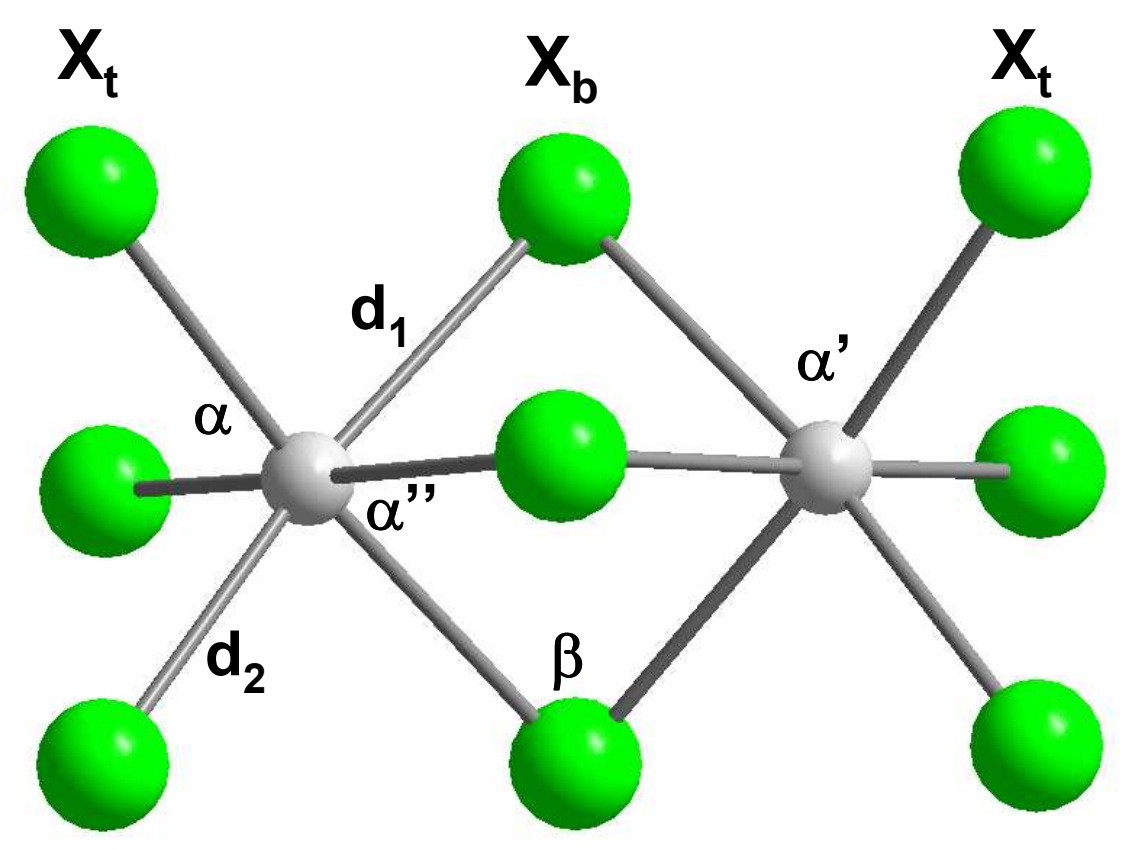

Figure 12 

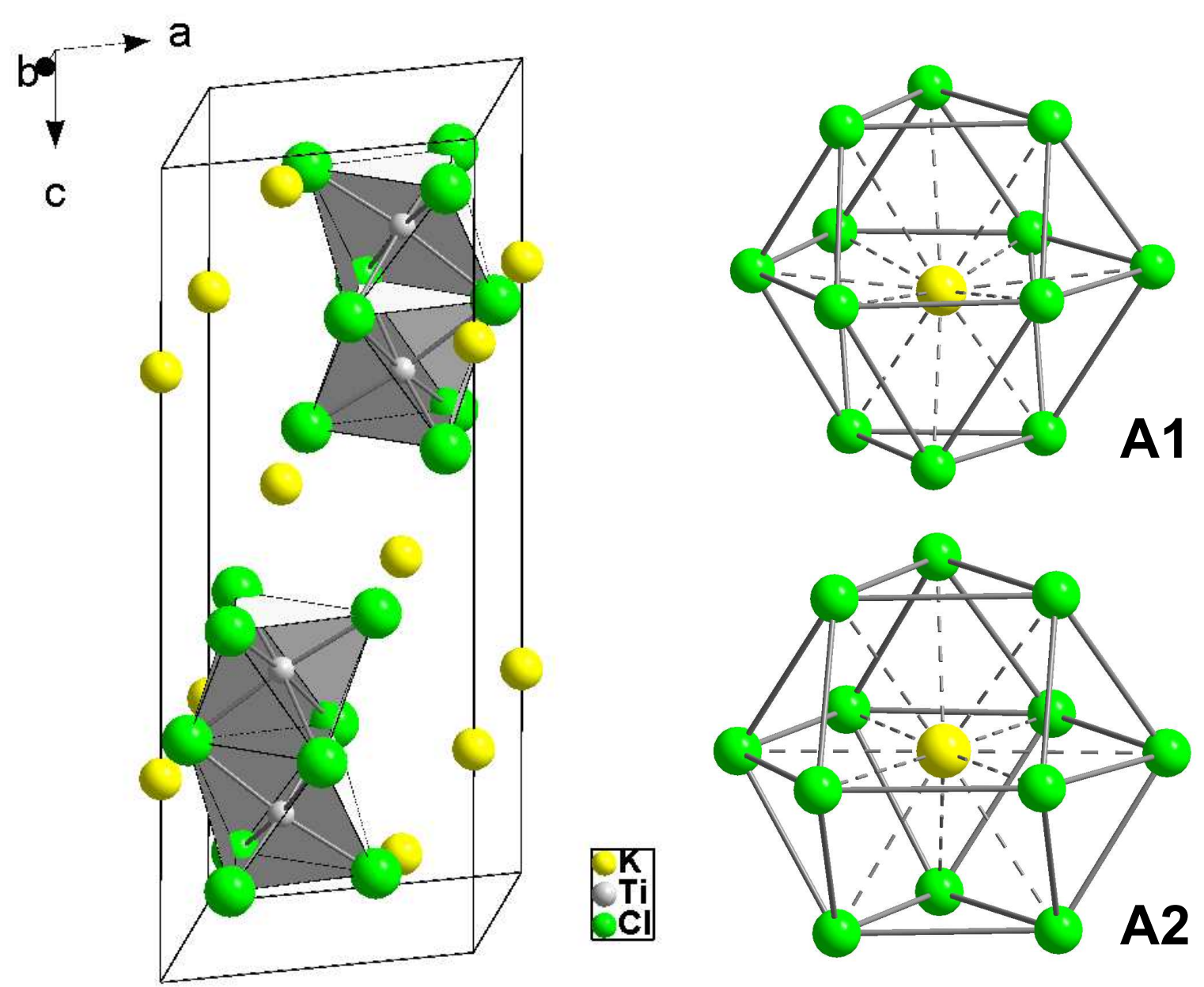

Figure 13 


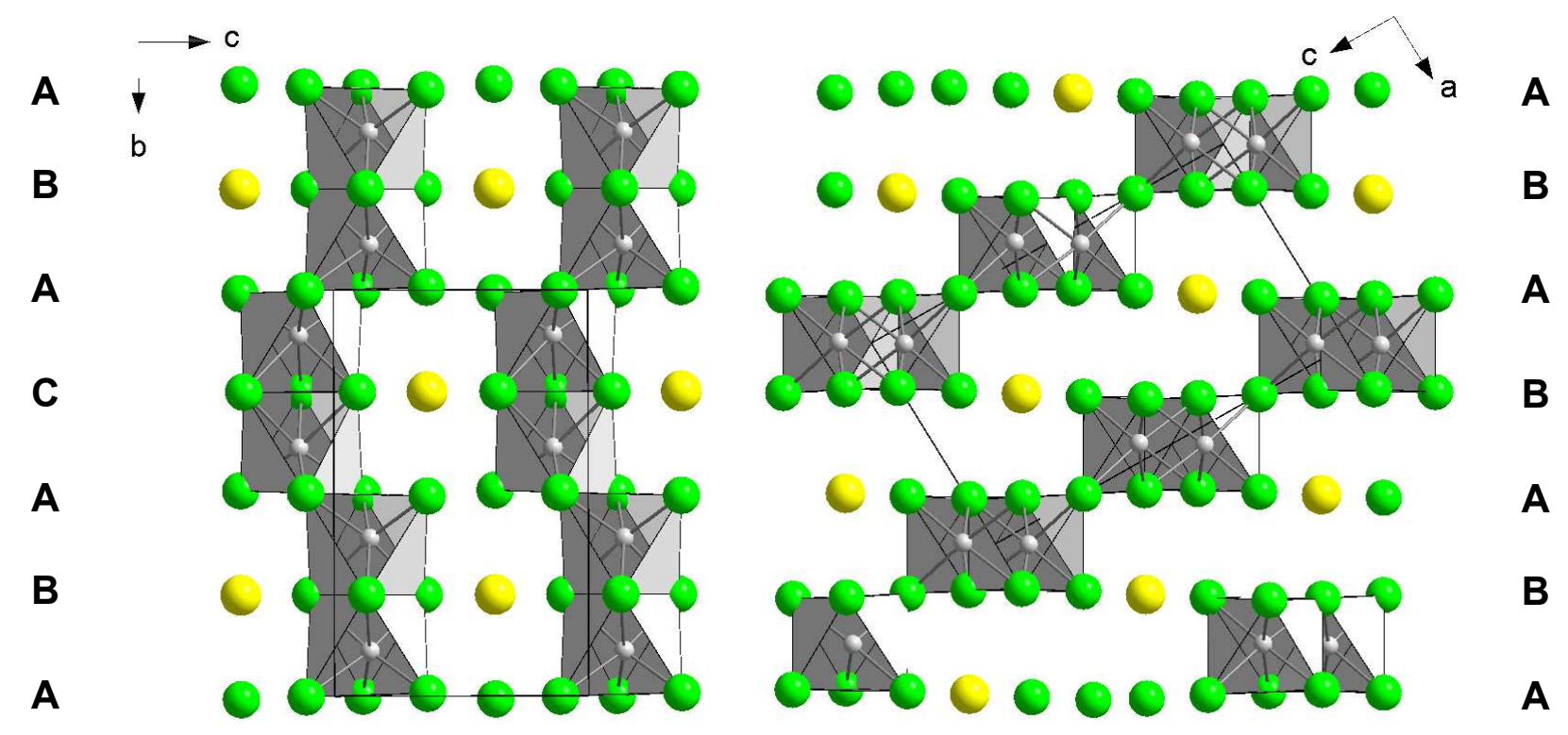

Figure 14 


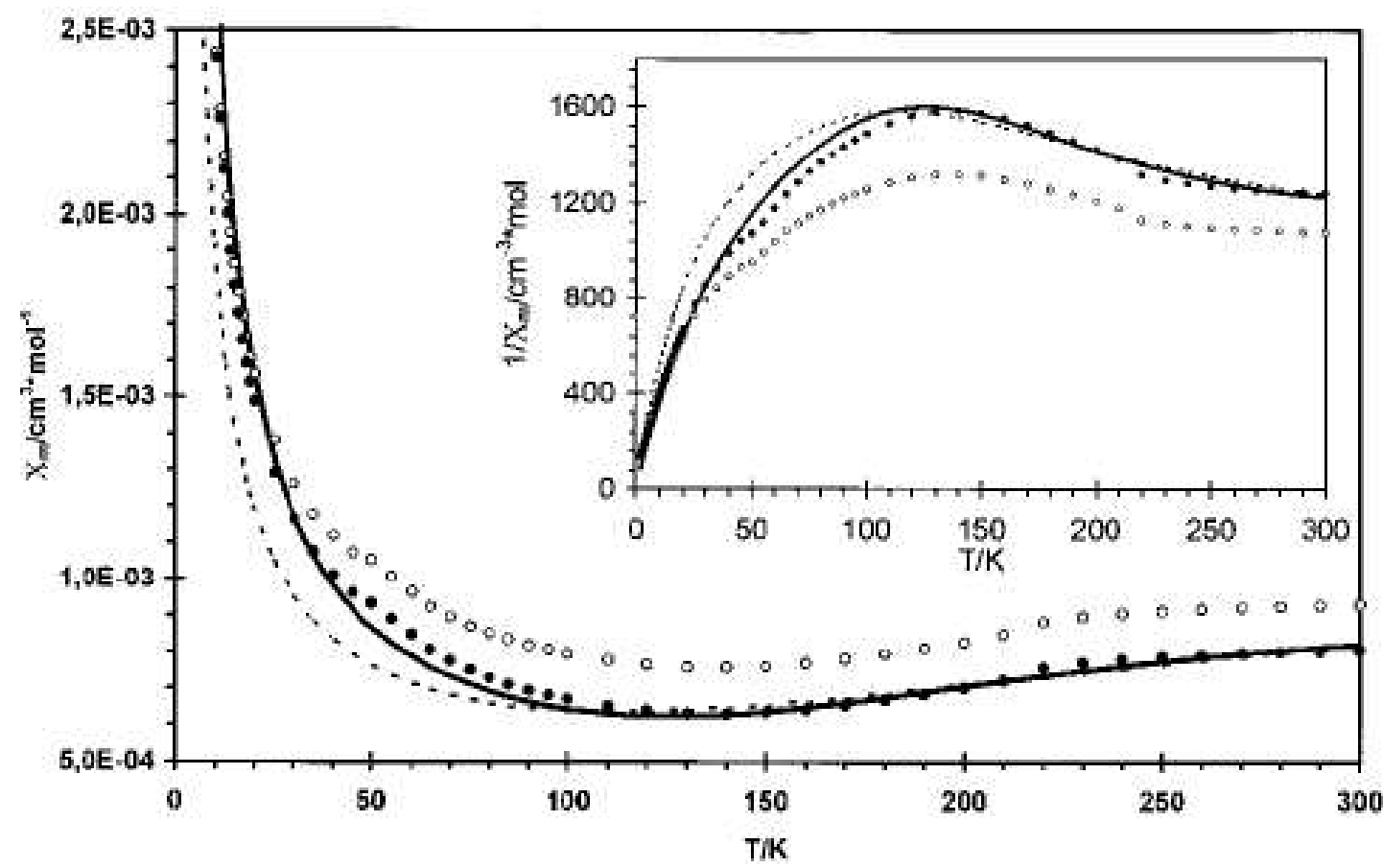

Figure 15 

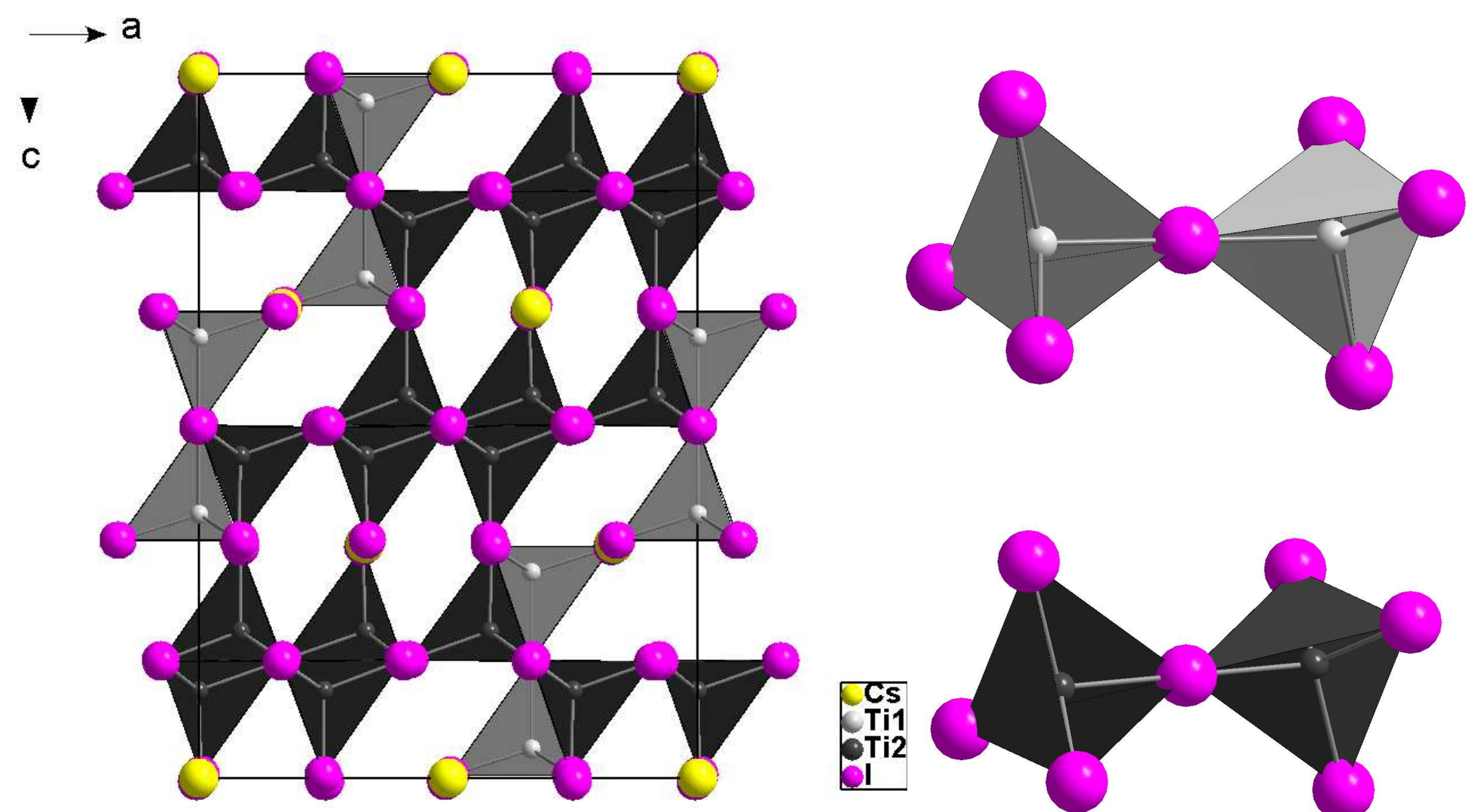

Figure 16

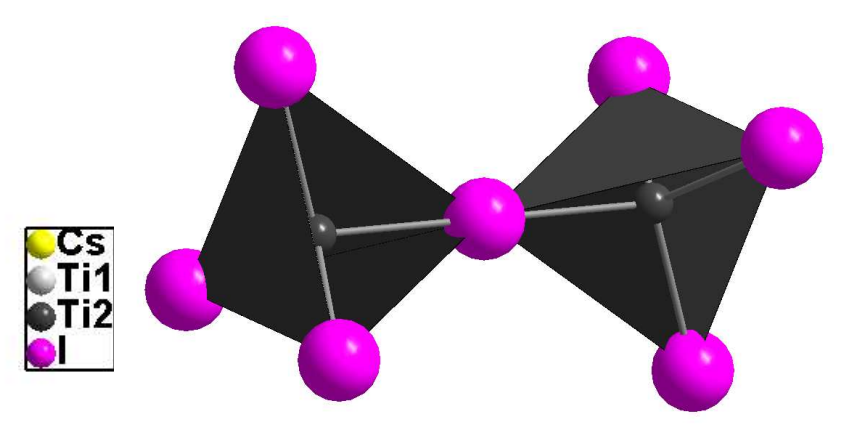




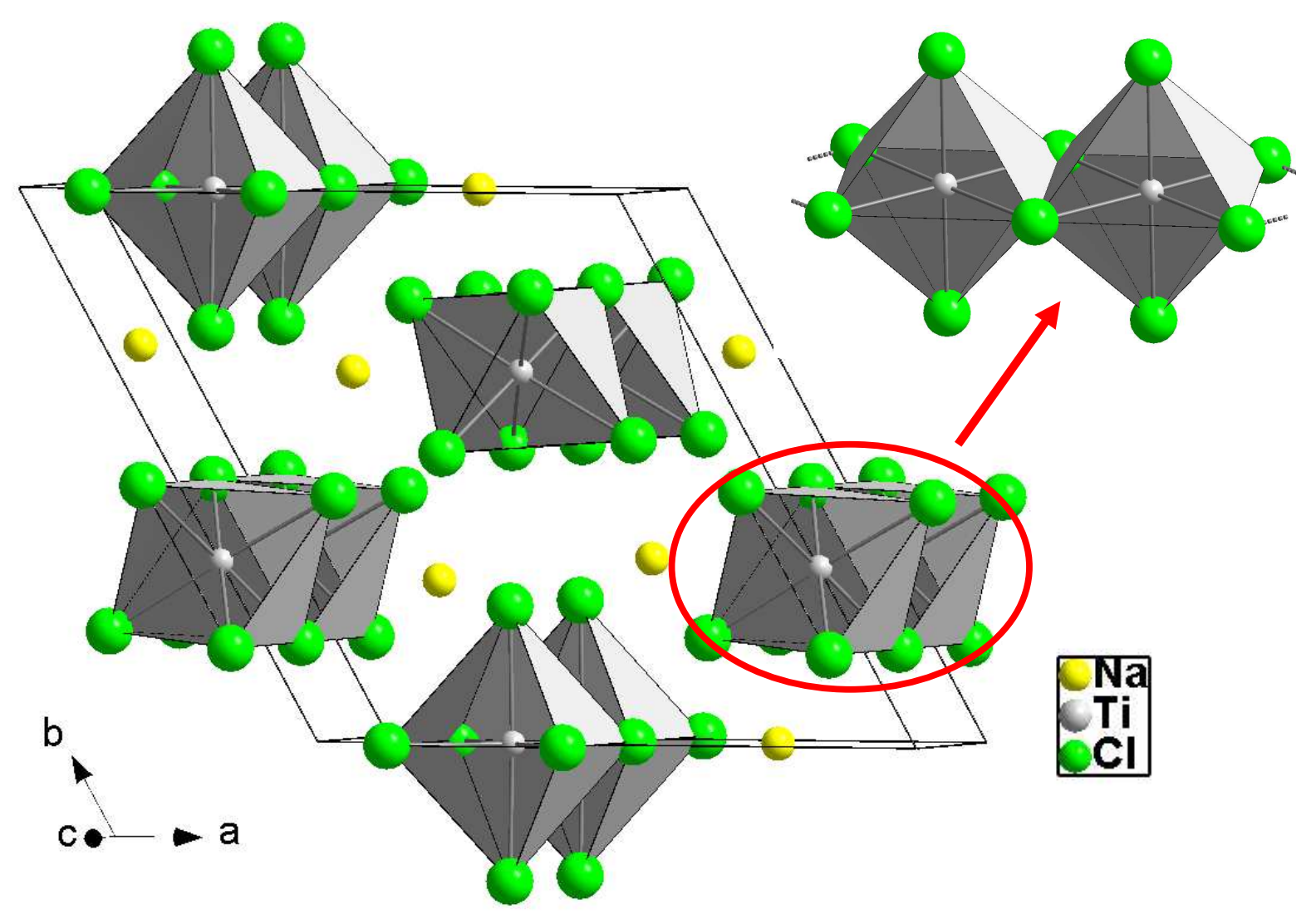

Figure 17 


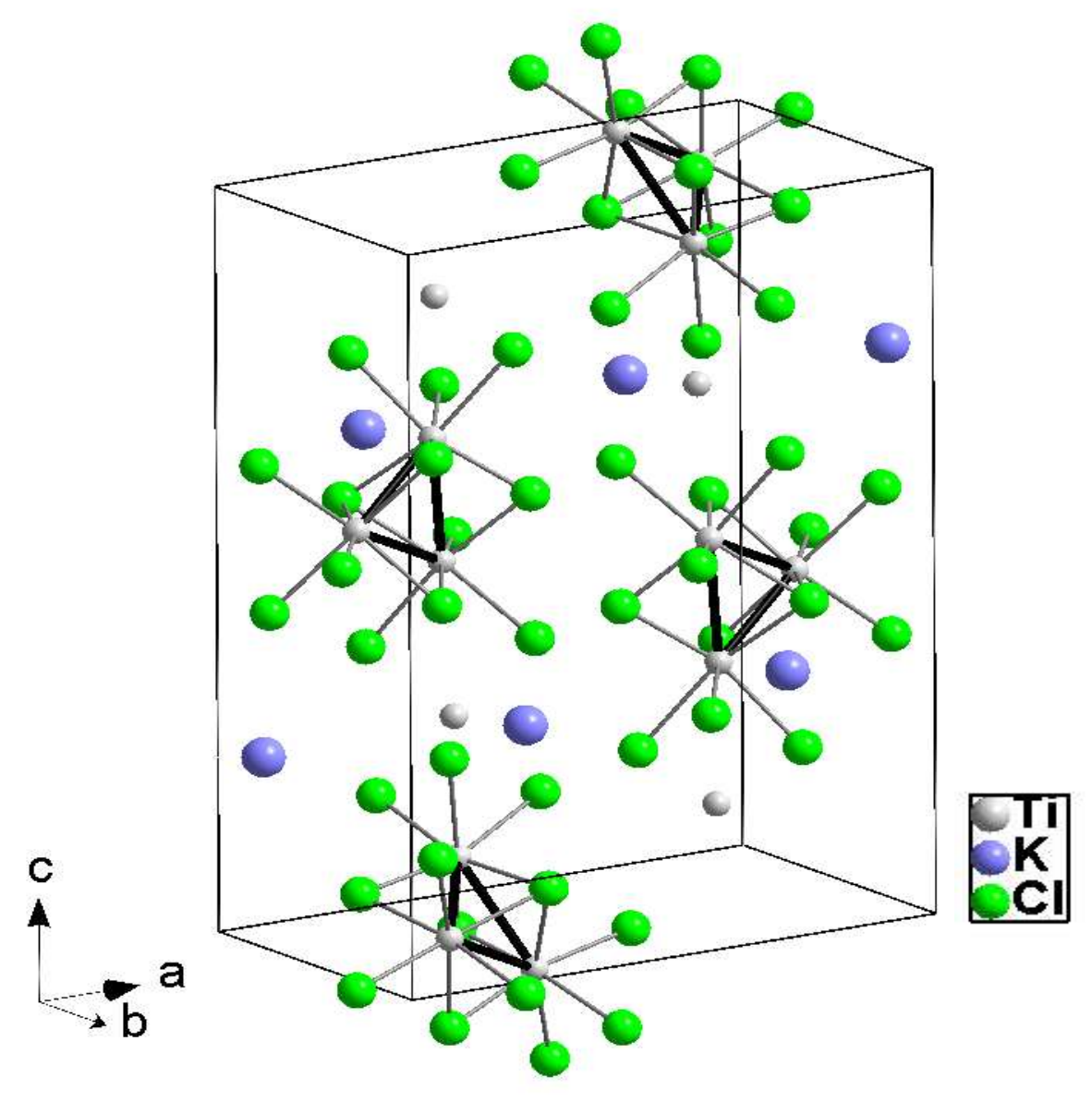

Figure 18 


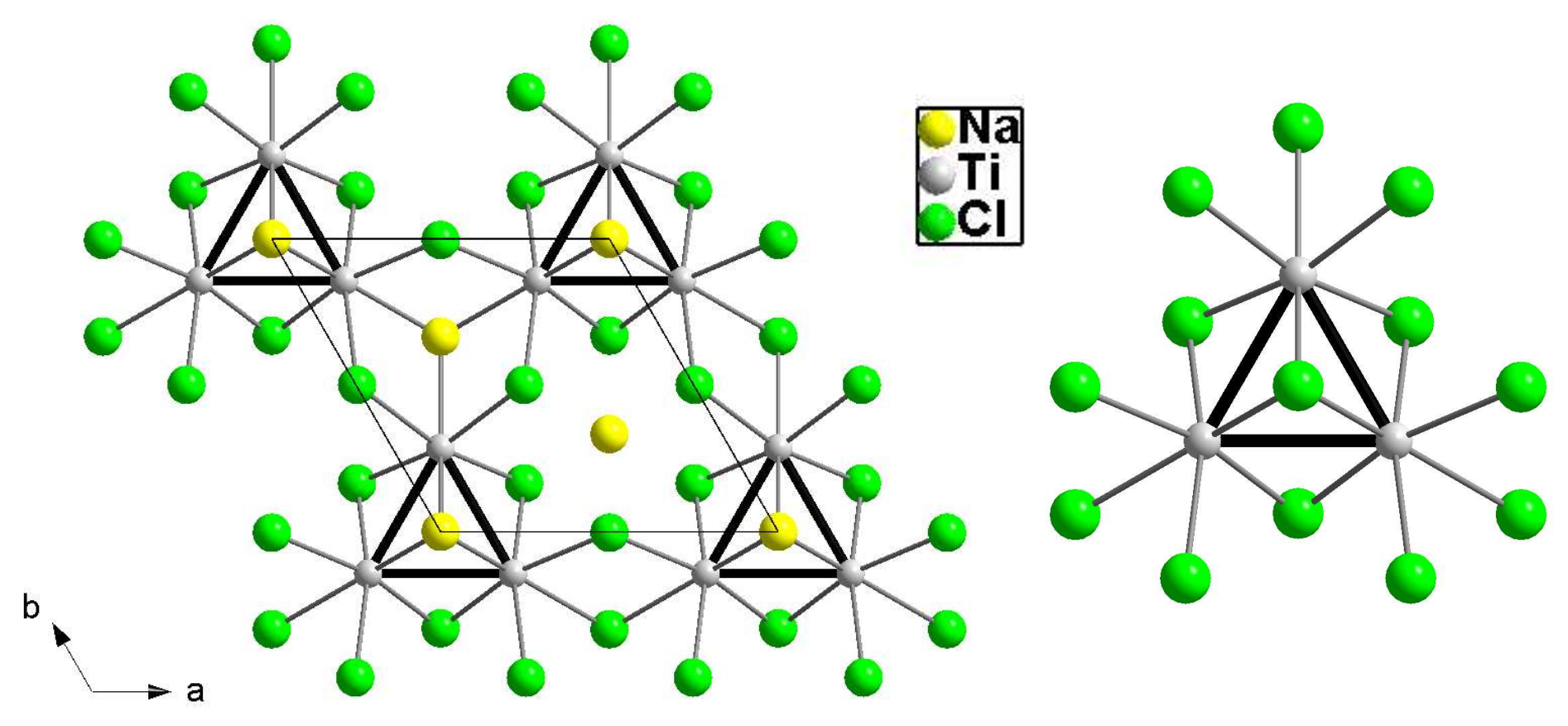

Figure 19 


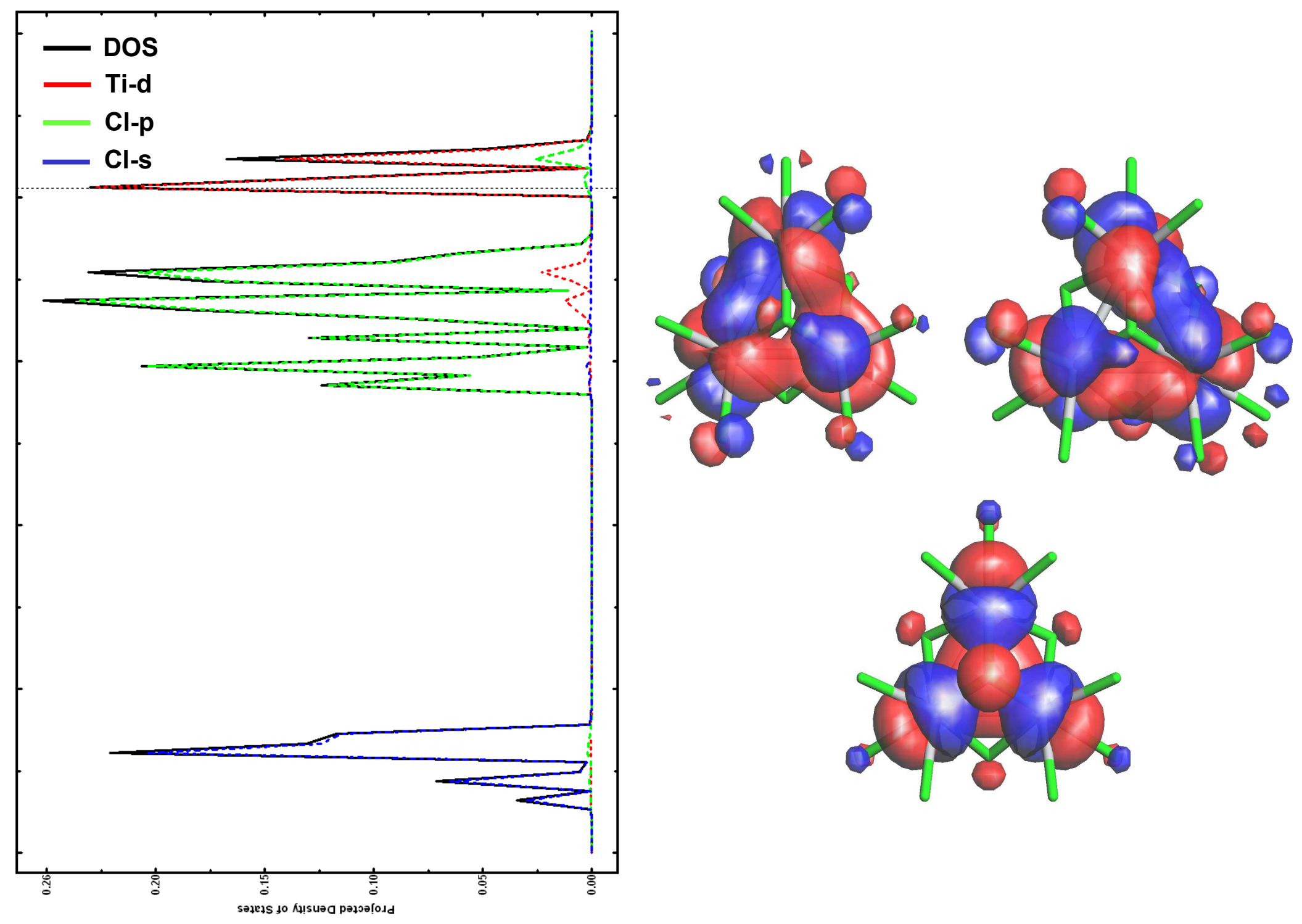

Figure 20 


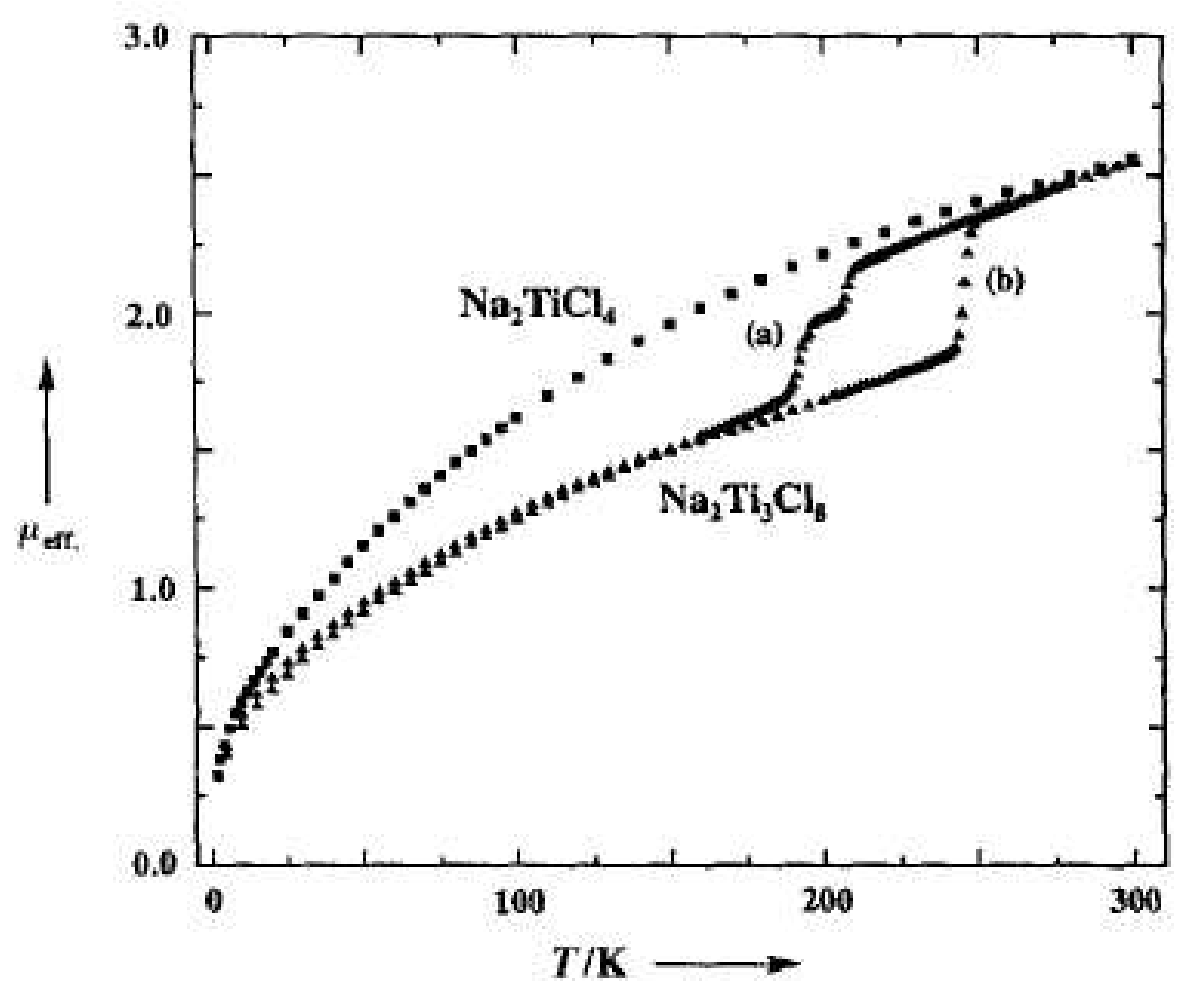

Figure 21 

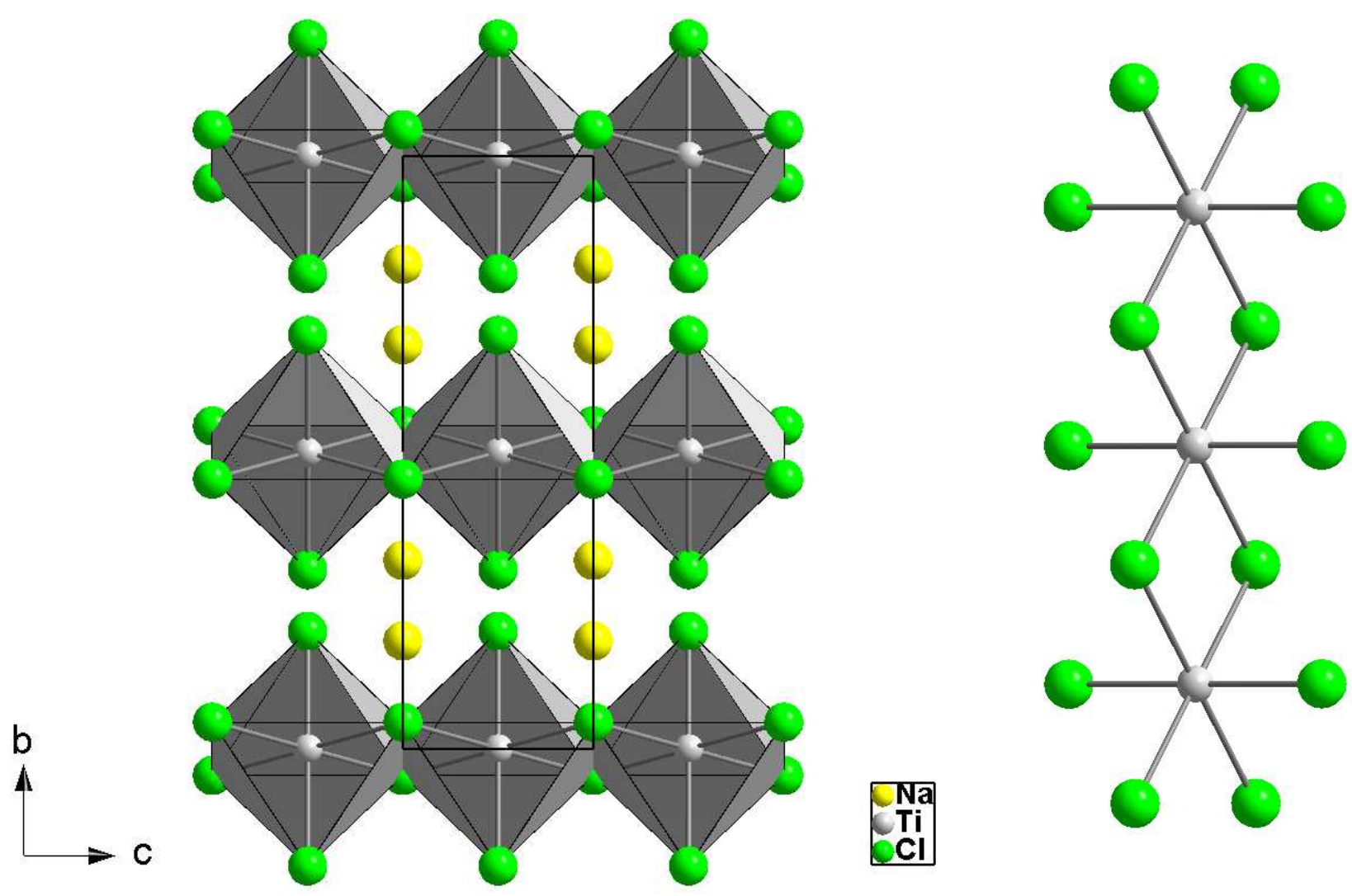

Figure 22 


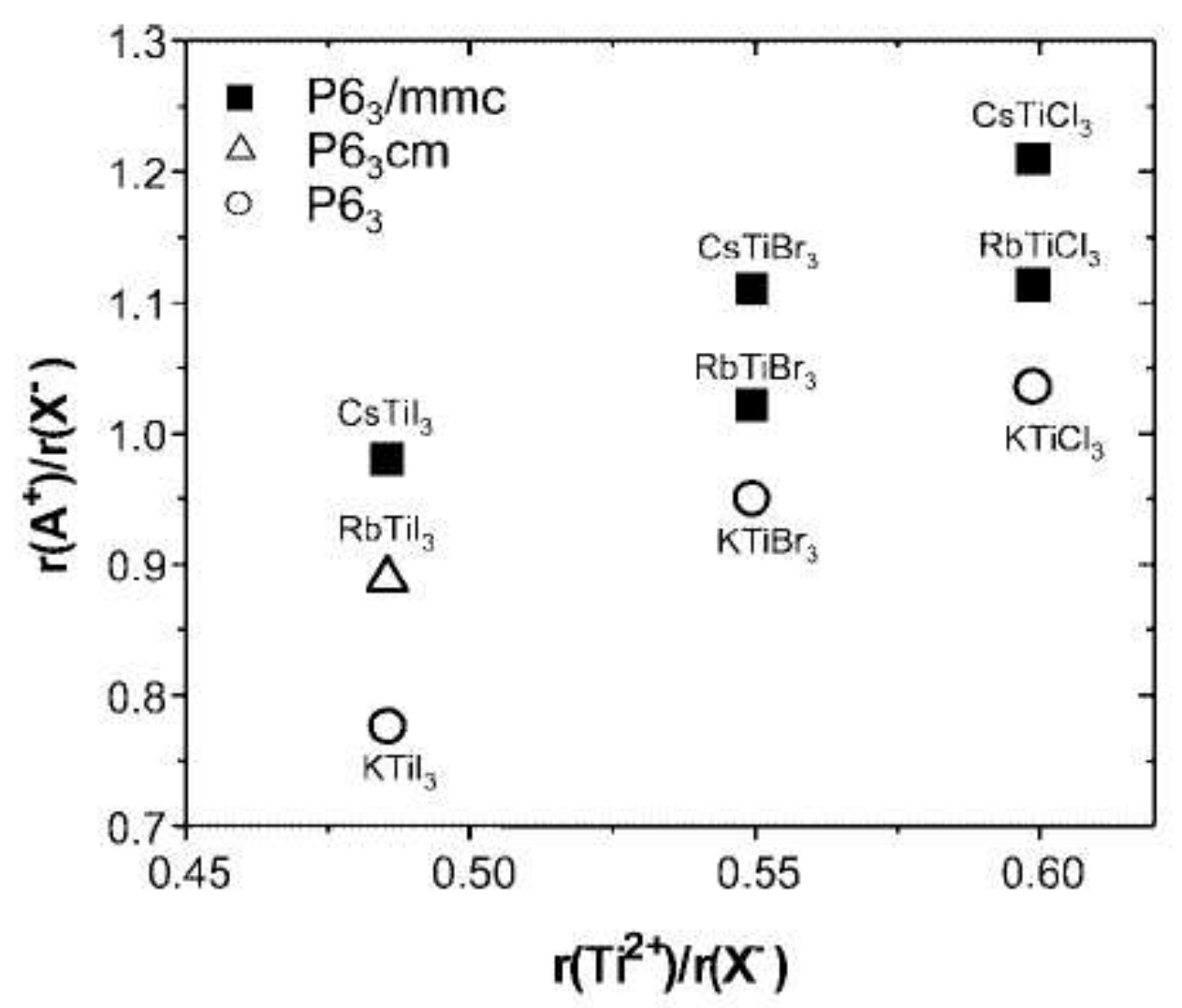

Figure 23 

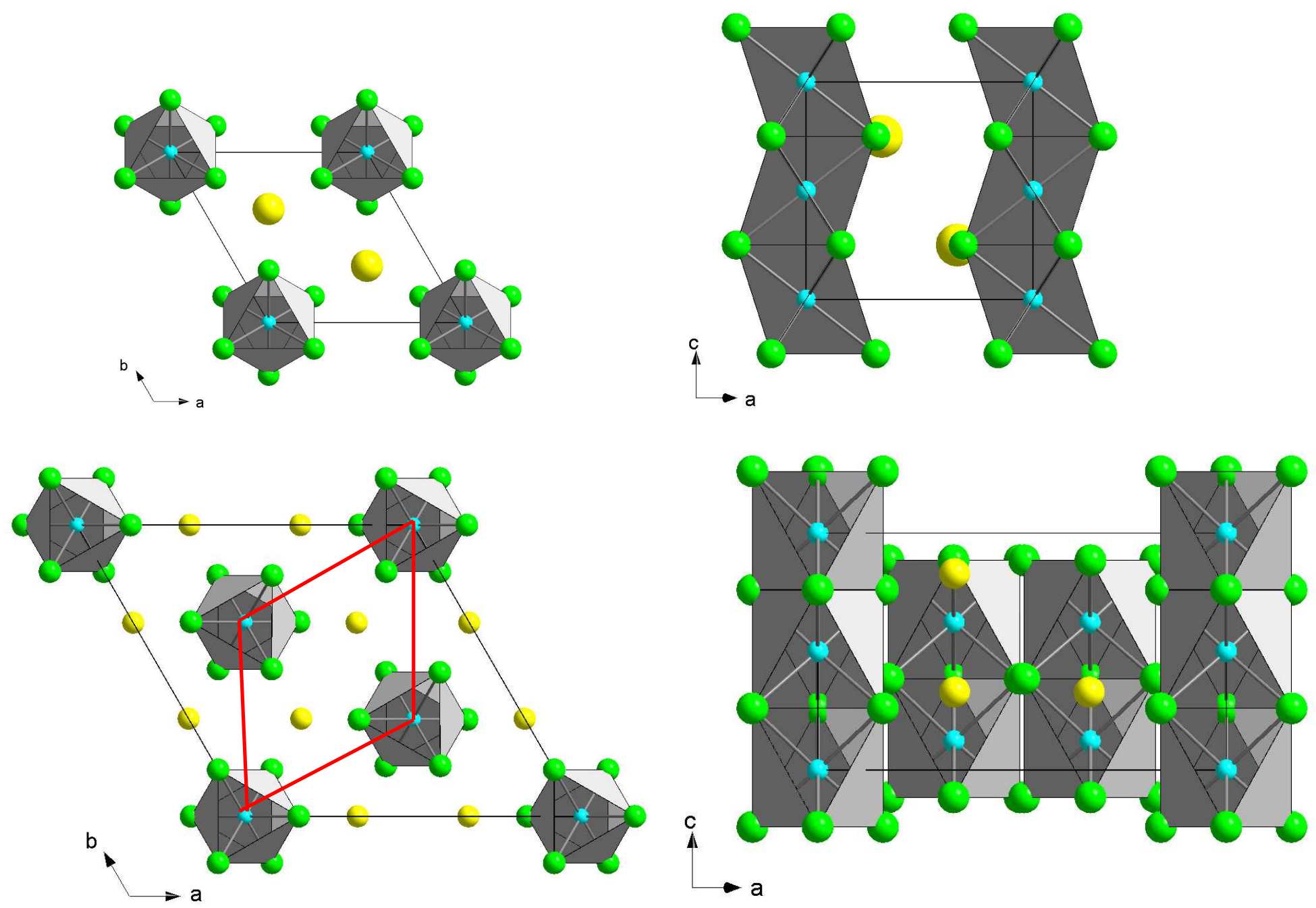

Figure 24 


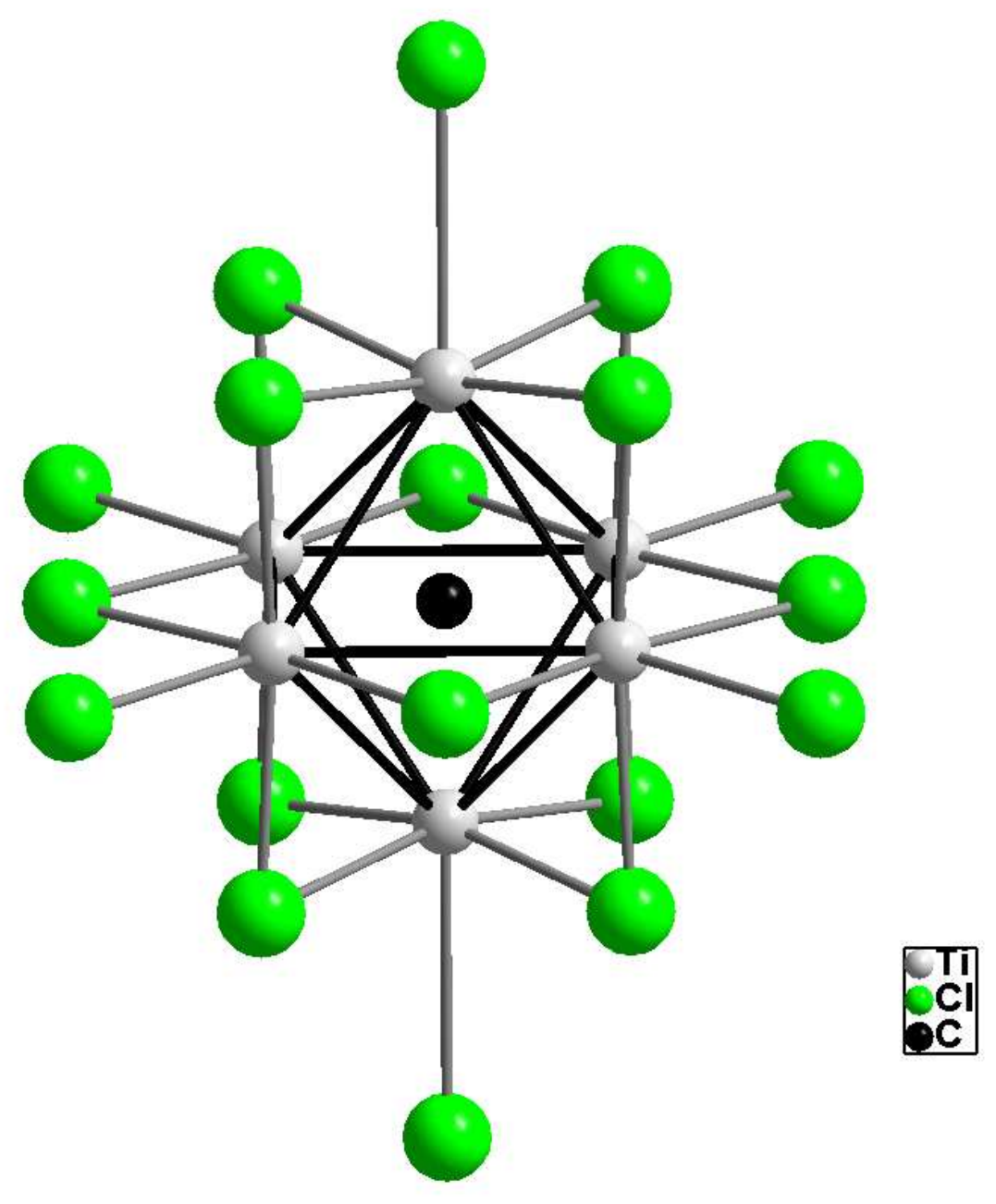

Figure 25 


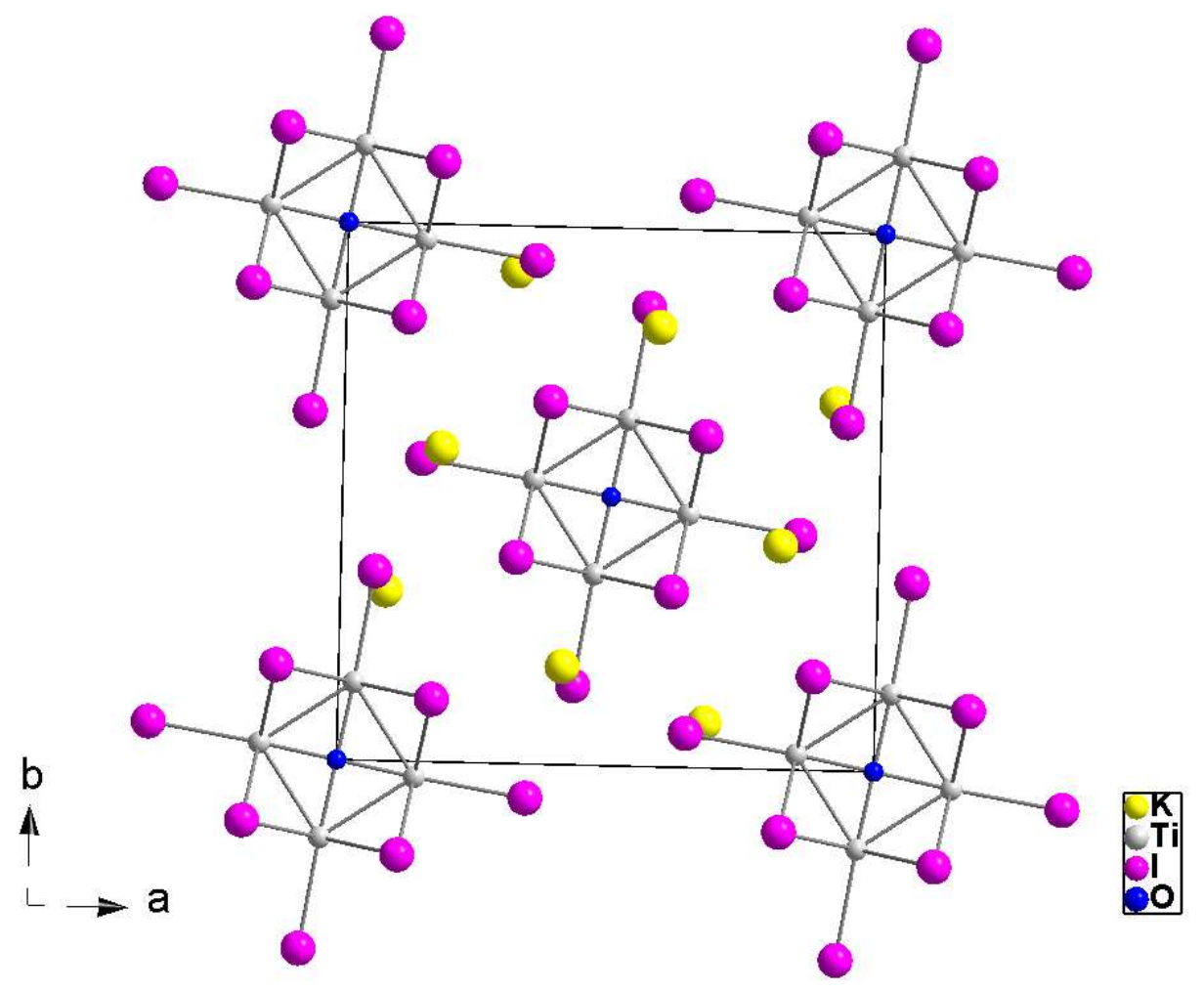

Figure 26 

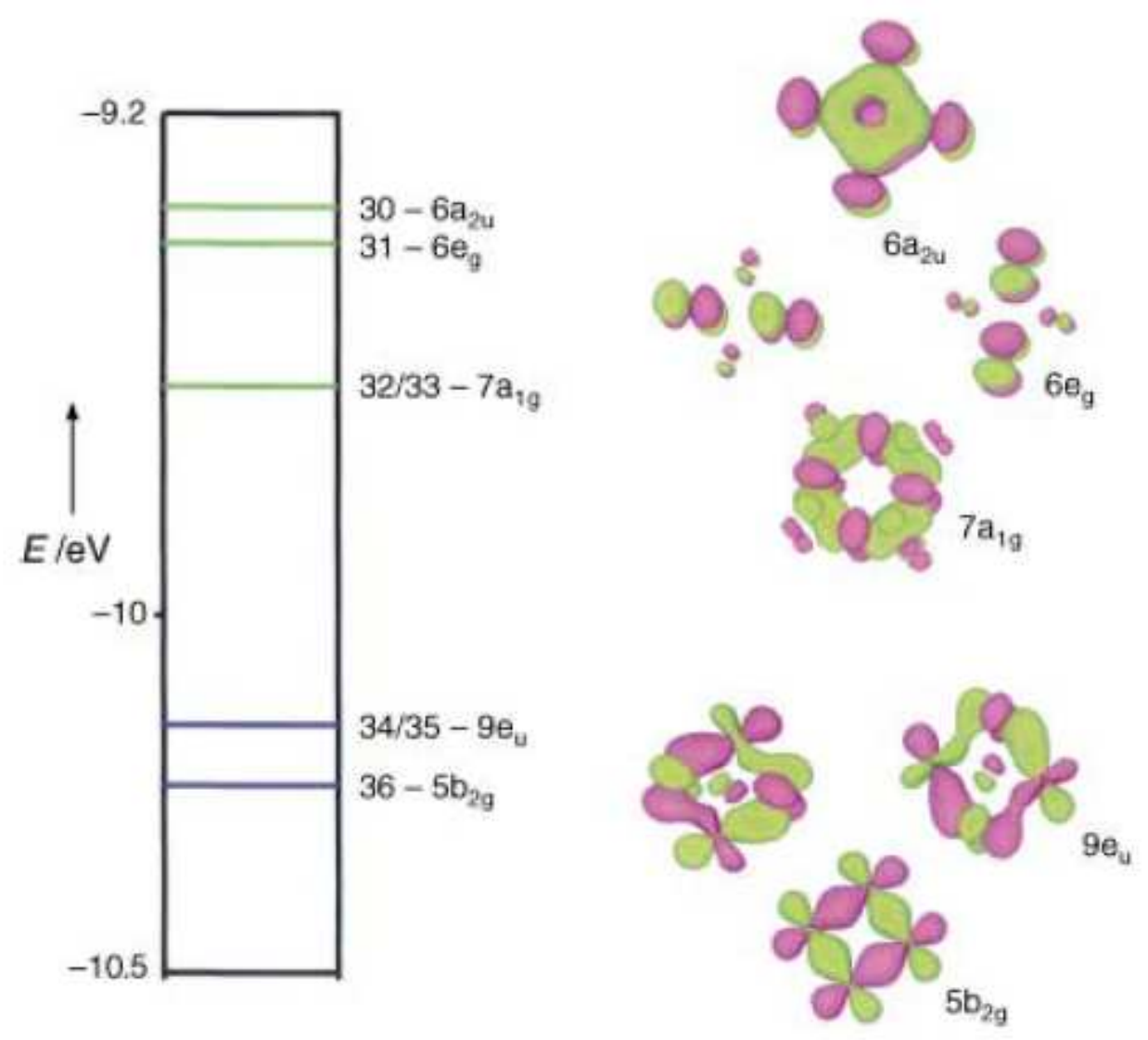

Figure 27 


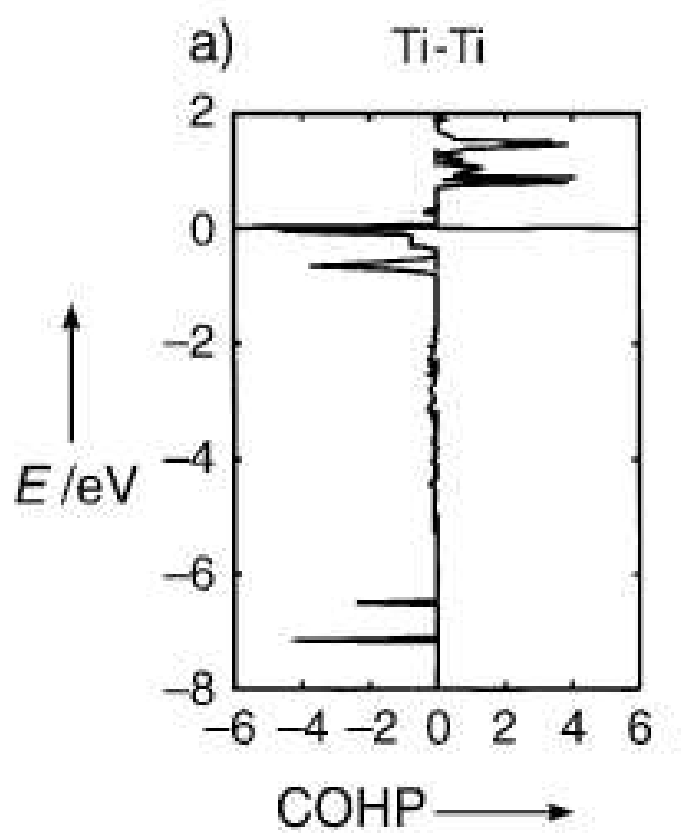

b) $\mathrm{Ti}-\mathrm{I}$

c) $\quad \mathrm{Ti}-\mathrm{O}$
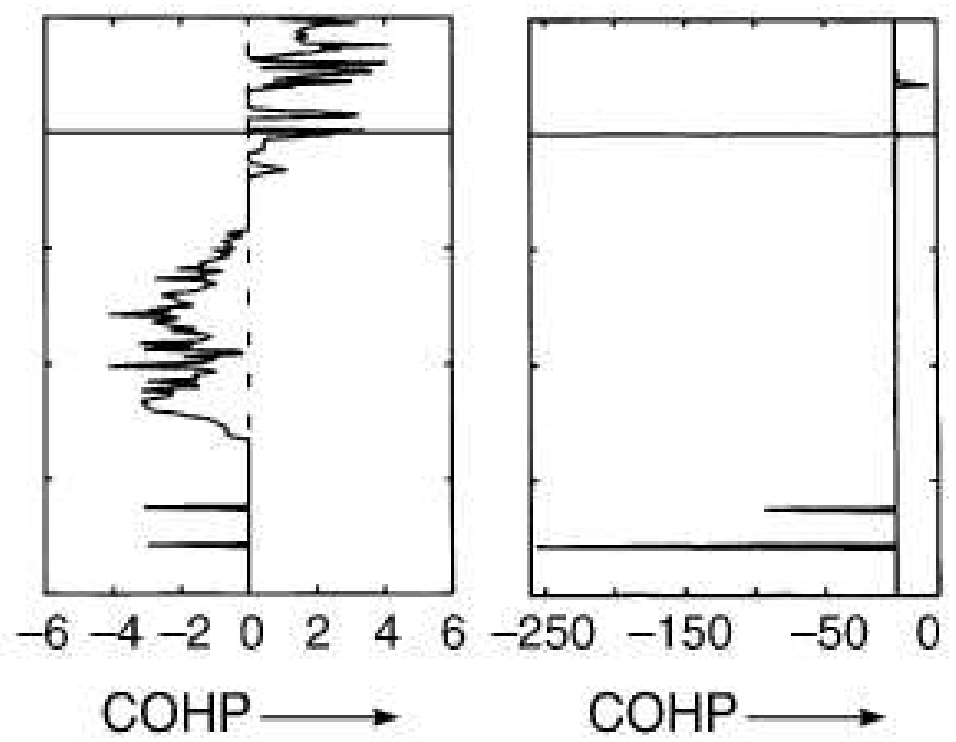

Figure 28 